\title{
Recent changes in terrestrial water storage in the Upper Nile Basin: an evaluation of commonly used gridded GRACE products
}

\author{
Mohammad Shamsudduha ${ }^{1,2}$, Richard G. Taylor ${ }^{2}$, Darren Jones ${ }^{3}$, Laurent Longuevergne ${ }^{4}$, Michael Owor ${ }^{5}$, and \\ Callist Tindimugaya ${ }^{6}$ \\ ${ }^{1}$ Institute for Risk and Disaster Reduction, University College London, London, UK \\ ${ }^{2}$ Department of Geography, University College London, London, UK \\ ${ }^{3}$ Centre for Geography, Environment and Society, University of Exeter, Exeter, UK \\ ${ }^{4}$ CNRS - UMR 6118 Géosciences Rennes, Université de Rennes 1, Rennes, France \\ ${ }^{5}$ Department of Geology \& Petroleum Studies, Makerere University, Kampala, Uganda \\ ${ }^{6}$ Directorate of Water Resources Management, Ministry of Water \& Environment, Entebbe, Uganda \\ Correspondence to: Mohammad Shamsudduha (m.shamsudduha@ucl.ac.uk)
}

Received: 14 March 2017 - Discussion started: 21 March 2017

Revised: 19 June 2017 - Accepted: 8 August 2017 - Published: 12 September 2017

\begin{abstract}
GRACE (Gravity Recovery and Climate Experiment) satellite data monitor large-scale changes in total terrestrial water storage $(\Delta \mathrm{TWS})$, providing an invaluable tool where in situ observations are limited. Substantial uncertainty remains, however, in the amplitude of GRACE gravity signals and the disaggregation of TWS into individual terrestrial water stores (e.g. groundwater storage). Here, we test the phase and amplitude of three GRACE $\triangle$ TWS signals from five commonly used gridded products (i.e. NASA's GRCTellus: CSR, JPL, GFZ; JPL-Mascons; GRGS GRACE) using in situ data and modelled soil moisture from the Global Land Data Assimilation System (GLDAS) in two sub-basins (LVB: Lake Victoria Basin; LKB: Lake Kyoga Basin) of the Upper Nile Basin. The analysis extends from January 2003 to December 2012, but focuses on a large and accurately observed reduction in $\triangle$ TWS of $83 \mathrm{~km}^{3}$ from 2003 to 2006 in the Lake Victoria Basin. We reveal substantial variability in current GRACE products to quantify the reduction of $\triangle \mathrm{TWS}$ in Lake Victoria that ranges from $80 \mathrm{~km}^{3}$ (JPL-Mascons) to 69 and $31 \mathrm{~km}^{3}$ for GRGS and GRCTellus respectively. Representation of the phase in TWS in the Upper Nile Basin by GRACE products varies but is generally robust with GRGS, JPL-Mascons, and GRCTellus (ensemble mean of CSR, JPL, and GFZ time-series data), explaining 90, 84, and $75 \%$ of the variance respectively in "in situ" or "bottom-up" $\Delta$ TWS in the LVB. Resolution of changes in groundwater storage ( $\triangle \mathrm{GWS}$ ) from GRACE $\triangle \mathrm{TWS}$ is greatly constrained by
\end{abstract}

both uncertainty in changes in soil-moisture storage $(\triangle \mathrm{SMS})$ modelled by GLDAS LSMs (CLM, NOAH, VIC) and the low annual amplitudes in $\triangle$ GWS (e.g. $1.8-4.9 \mathrm{~cm}$ ) observed in deeply weathered crystalline rocks underlying the Upper Nile Basin. Our study highlights the substantial uncertainty in the amplitude of $\triangle$ TWS that can result from different data-processing strategies in commonly used, gridded GRACE products; this uncertainty is disregarded in analyses of $\triangle$ TWS and individual stores applying a single GRACE product.

\section{Introduction}

Satellite measurements under the Gravity Recovery and Climate Experiment (GRACE) mission have, since March 2002 (Tapley et al., 2004), enabled remote monitoring of large-scale (i.e. GRACE footprint: $\sim 200000 \mathrm{~km}^{2}$ ), spatiotemporal changes in total terrestrial water storage ( $\triangle \mathrm{TWS}$ ) at 10-day to monthly timescales (Longuevergne et al., 2013; Humphrey et al., 2016). Over the last 15 years, studies in basins around the world (Rodell and Famiglietti, 2001; Strassberg et al., 2007; Leblanc et al., 2009; Chen et al., 2010; Longuevergne et al., 2010; Frappart et al., 2011; Jacob et al., 2012; Shamsudduha et al., 2012; Arendt et al., 2013; Kusche et al., 2016) have demonstrated that GRACE satellites trace natural (e.g. drought, floods, 
glacier and ice melting, sea-level rise) and anthropogenic (e.g. abstraction-driven groundwater depletion) influences on $\triangle$ TWS. GRACE-derived TWS provides vertically integrated water storage changes in all water-bearing layers (Wahr et al., 2004; Strassberg et al., 2007; Ramillien et al., 2008) that include (Eq. 1) surface water storage in rivers, lakes, and wetlands ( $\triangle \mathrm{SWS})$, soil moisture storage $(\triangle \mathrm{SMS})$, ice and snow water storage $(\triangle \mathrm{ISS})$, and groundwater storage $(\Delta \mathrm{GWS})$. Over the last decade, GRACE measurements have become an important hydrological tool for quantifying basin-scale $\Delta$ TWS (Güntner, 2008; Xie et al., 2012; Hu and Jiao, 2015) and are increasingly being used to assess spatio-temporal changes in specific water stores (Famiglietti et al., 2011; Shamsudduha et al., 2012; Jiang et al., 2014; Castellazzi et al., 2016; Long et al., 2016; Nanteza et al., 2016) where timeseries records of other individual freshwater stores are available (Eq. 1).

$\Delta \mathrm{TWS}_{t}=\Delta \mathrm{GWS}_{t}+\Delta \mathrm{ISS}_{t}+\Delta \mathrm{SWS}_{t}+\Delta \mathrm{SMS}_{t}$

GRACE-derived $\Delta$ TWS derive from monthly gravitational fields which can be represented as spherical harmonic coefficients that are noisy as depicted in north-south elongated linear features or "stripes" on monthly global gravity maps (Swenson and Wahr, 2006; Wang et al., 2016). Post-processing of GRACE SH data is therefore required. The most popular GRACE products are NASA's GRCTellus land gravity solutions (i.e. spherical harmonics based CSR, JPL, and GFZ), which require scaling factors to recover spatially smoothed TWS signals (Swenson and Wahr, 2006; Landerer and Swenson, 2012). Additionally, NASA's new monthly gridded GRACE product, Mass Concentration blocks (i.e. Mascons), estimates terrestrial mass changes directly from inter-satellite acceleration measurements and can be used without further post-processing (Rowlands et al., 2010; Watkins et al., 2015). GRGS GRACE products are also spherical harmonic-based, available at a 10-day time step, and can also be used directly since gravity fields are stabilized during the processing of GRACE satellite data (Lemoine et al., 2007; Bruinsma et al., 2010).

Restoration of the amplitude of GRCTellus TWS data, dampened by spatial Gaussian filtering with a large smoothing radius (e.g. $300-500 \mathrm{~km}$ ), is commonly achieved using scaling factors that derive from a priori models of freshwater stores, usually a global-scale land-surface model or LSM (Long et al., 2015). However, signal-restoration methods are emerging that do not require hydrological models or LSMs (Vishwakarma et al., 2016). Substantial uncertainty nevertheless persists in the magnitude of applied scaling factors (e.g. GRCTellus) and corrections (Long et al., 2015). Recent global-scale analyses have evaluated variability in the amplitude of $\triangle T W S$ in various GRACE products (Scanlon et al., 2016) and compared these with evidence from global hydrological and land-surface models (Long et al., 2017); these studies highlight well uncertainties in the amplitude of
$\Delta$ TWS, but are not reconciled to observations. In situ observations provide a valuable and necessary constraint to the scaling of TWS signals over a particular study area, as no consistent basis for ground-truthing these factors exists.

The disaggregation of GRACE-derived $\triangle$ TWS anomalies into individual water stores (Eq. 1) is commonly constrained by the limited availability of observations of terrestrial freshwater stores (i.e. $\Delta$ SWS, $\triangle$ SMS, $\Delta$ GWS, and $\Delta \mathrm{ISS}$ ). Indeed, a major source of uncertainty in the attribution of GRACE $\triangle$ TWS derives from the continued reliance on modelled $\triangle$ SMS derived from LSMs (i.e. CLM, NOAH, VIC, and MOSAIC) under the Global Land Data Assimilation System or GLDAS (Rodell et al., 2004) and remote-sensing products (Shamsudduha et al., 2012; Khandu et al., 2016). Further, analyses of GRACE-derived $\Delta$ GWS often assume $\Delta$ SWS is limited (Kim et al., 2009), yet studies in the humid tropics and engineered systems challenge this assumption, showing that it can overestimate $\Delta$ GWS (Shamsudduha et al., 2012; Longuevergne et al., 2013). Robust estimates of $\triangle$ GWS from GRACE gravity signals have, to date, been developed in locations where $\Delta$ SWS is well constrained by in situ observations and groundwater is used intensively for irrigation so that $\Delta$ GWS comprises a significant $(>10 \%$ ) proportion of $\Delta$ TWS (Leblanc et al., 2009; Famiglietti et al., 2011; Shamsudduha et al., 2012; Scanlon et al., 2015). In sub-Saharan Africa, intensive groundwater withdrawals are restricted to a limited number of locations (e.g. irrigation schemes, cities) and constrained by low-storage, low-transmissivity aquifers in the deeply weathered crystalline rocks that underlie $\sim 40 \%$ of this region (MacDonald et al., 2012), including the Upper Nile Basin (Fig. 1). Consequently, the ability of low-resolution GRACE gravity signals to trace $\triangle \mathrm{GWS}$ in these hard-rock environments is unclear. A recent study (Nanteza et al., 2016) applies NASA's GRCTellus (CSR GRACE) data over large basin areas $\left(>300000 \mathrm{~km}^{2}\right)$ of eastern Africa and argues that $\Delta$ GWS can be estimated with sufficient reliability to characterize regional groundwater systems after accounting for $\triangle$ SWS by satellite altimetry and $\triangle$ SMS data from the GLDAS LSM ensemble (Rodell et al., 2004).

Here, we exploit a large-scale reduction and recovery in surface water storage that was recorded within Lake Victoria (Fig. 1), the world's second largest lake by surface area $\left(67220 \mathrm{~km}^{2}\right)$ (UNEP, 2013) and eighth largest by volume $\left(2760 \mathrm{~km}^{3}\right.$ ) (Awange et al., 2008). This well-constrained reduction in $\triangle$ SWS comprises a decline in lake level of $1.2 \mathrm{~m}$ between May 2004 and February 2006, equivalent to a lake-water volume ( $\triangle$ SWS $)$ loss of $81 \mathrm{~km}^{3}$ that resulted, in part, from excessive dam releases (Fig. 2). We test the ability of current GRACE products to represent the amplitude and phase of this voluminous and well-constrained change in freshwater storage. Our analysis focuses on both the Lake Victoria Basin (hereafter LVB) $\left(256100 \mathrm{~km}^{2}\right)$ and Lake Kyoga Basin (hereafter LKB) $\left(79270 \mathrm{~km}^{2}\right.$ ) (Fig. 1). Applying in situ observations of $\triangle$ SWS and $\Delta$ GWS com- 


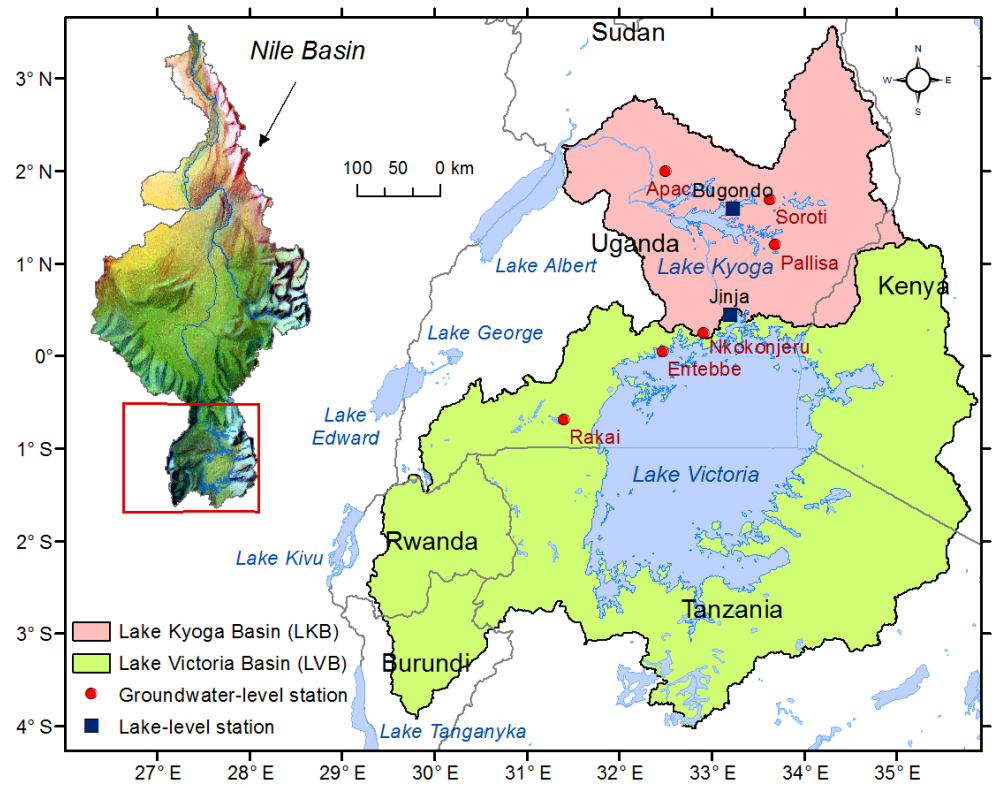

Figure 1. Map of the study area encompassing the Lake Victoria Basin (LVB) and Lake Kyoga Basin (LKB), and location of the in situ monitoring stations. The Upper Nile Basin is marked by a rectangle (red) within the entire Nile River Basin shown as a shaded relief index map. Piezometric monitoring (red circles) and lake-level gauging (dark blue squares) stations are shown on the map.

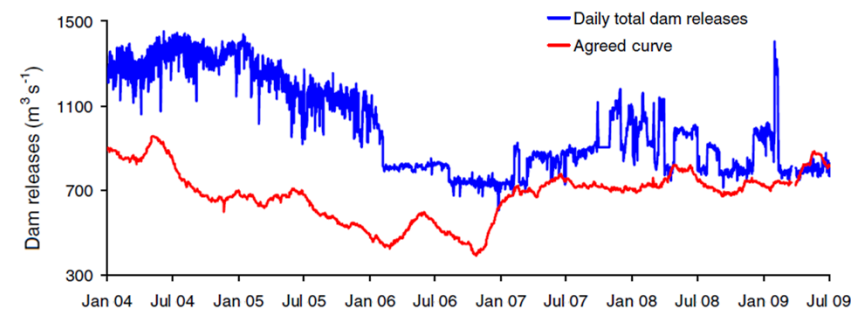

Figure 2. Observed daily total dam releases (blue line) and the agreed curve (red line) at the outlet of Lake Victoria in Jinja from November 2007 to July 2009 (Owor et al., 2011).

bined with simulated $\triangle$ SMS by the GLDAS LSMs, we assess (1) the ability of current gridded GRACE products (i.e. GRCTellus, JPL-Mascons, and GRGS GRACE) to measure a well-constrained $\triangle$ TWS in the Upper Nile Basin from 2003 to 2012 , focusing on the unintended experiment within the LVB from 2003 to 2006; and (2) the sensitivity of disaggregated GRACE $\triangle$ TWS signals to trace $\triangle$ GWS in a deeply weathered crystalline rock aquifer system underlying the Upper Nile Basin.

\section{The Upper Nile Basin}

\subsection{Hydroclimatology}

The Upper Nile Basin, the headwater area of the $\sim 3400000 \mathrm{~km}^{2}$ Nile Basin (Awange et al., 2014), includes both the LVB and LKB. Mean annual rainfall over the entire basin varies from 650 to $2900 \mathrm{~mm}$ (TRMM monthly rainfall; 2003-2012), with an average of $1300 \mathrm{~mm}$ and a standard deviation of $354 \mathrm{~mm}$ (Fig. 3). Mean annual gauged rainfall at different stations, Jinja, Bugondo, and Entebbe, measured 1195,1004 , and $1541 \mathrm{~mm}$ respectively (Owor et al., 2011). Rainfall over Lake Victoria is typically 25-30\% greater than that measured in the surrounding catchment (Fig. 3), which is partially explained by the nocturnal "lake breeze" effect (Yin and Nicholson, 1998; Nicholson et al., 2000; Owor et al., 2011).

Estimates of mean annual evaporation from the surface of Lake Victoria vary from $1260 \mathrm{~mm}$ (UNEP, 2013) to $1566 \mathrm{~mm}$ (Hoogeveen et al., 2015), whereas mean annual evaporation from the surface of Lake Kyoga is estimated to vary from $1205 \mathrm{~mm}$ (Brown and Sutcliffe, 2013) to $1660 \mathrm{~mm}$ (Hoogeveen et al., 2015). Evapotranspirative fluxes from the surrounding swamps in Lake Kyoga are estimated to be much higher and approximately $2230 \mathrm{~mm} \mathrm{yr}^{-1}$ (Brown and Sutcliffe, 2013).

Annual rainfall is predominantly bimodal in distribution (Fig. 4), with two distinct rainy seasons driven by the movement of the Intertropical Convergence Zone (ITCZ) (Awange et al., 2013). Long rains (March-May) and short rains (September-November) account for approximately 40 and $25 \%$ of annual rainfall respectively (Basalirwa, 1995; Indeje et al., 2000). The latter rainfalls are particularly influenced by the El Niño-Southern Oscillation (ENSO) and the Indian Ocean Dipole (IOD). GRACE-derived $\triangle$ TWS within the LVB shows a statistical association $\left(R^{2}\right)$ of 0.56 with ENSO and 0.48 with IOD (Awange et al., 2014). 


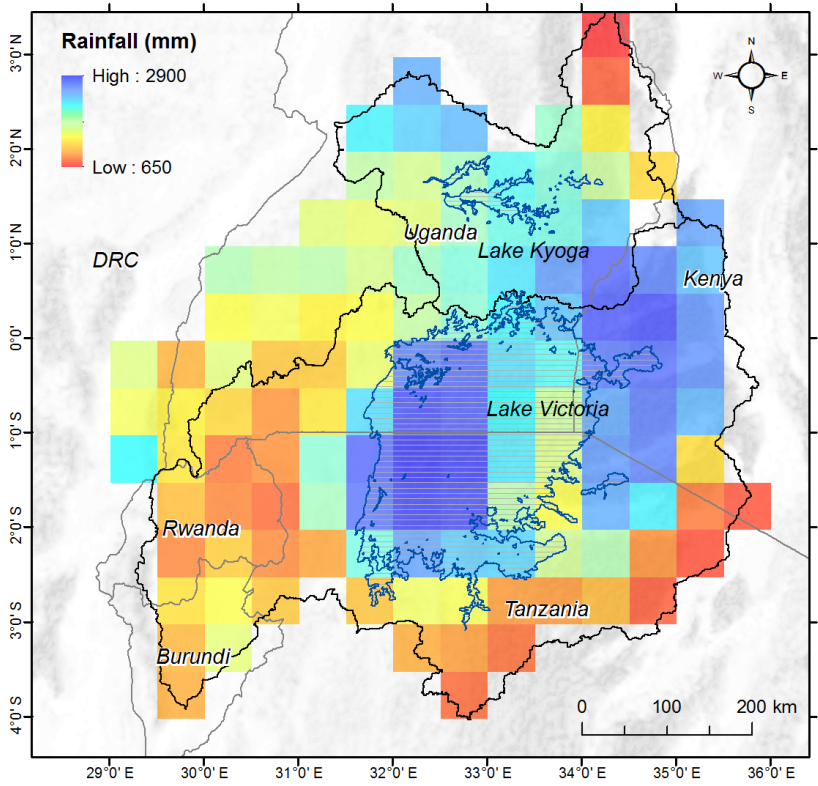

Figure 3. Mean annual rainfall for the period of 2003-2012 derived from TRMM satellite observations. Greater annual rainfall is observed over much of Lake Victoria and the north-eastern corner of the Lake Victoria Basin.

\subsection{Lakes Victoria and Kyoga}

Located between the $31^{\circ} 39^{\prime}$ and $34^{\circ} 53^{\prime} \mathrm{E}$ longitudes, and the $0^{\circ} 20^{\prime} \mathrm{N}$ and $3^{\circ} 00^{\prime} \mathrm{S}$ latitudes, Lake Victoria (Fig. 1) is located in Tanzania, Uganda, and Kenya, where each accounts for 51,43 , and $6 \%$ of the lake surface area respectively (Kizza et al., 2012). Lake Victoria is relatively shallow, with a mean depth of $\sim 40 \mathrm{~m}$ and a maximum depth of $84 \mathrm{~m}$ (UNEP, 2013) akin to many shallow, open surface-water bodies as well as permanent and seasonal wetlands occupying low-relief plateaus across the Great Lakes Region of Africa (Owor et al., 2011). Moreover, the western and north-western lake bathymetry is characterized by even shallower depths of between 4 and $7 \mathrm{~m}$ (Owor, 2010). Hydrologically, lake input is dominated by direct rainfall ( $84 \%$ of total input); the remainder derives primarily from river inflows as direct groundwater inflow $(<1 \%)$ is negligible (Owor et al., 2011). Approximately 25 major rivers flow into Lake Victoria, with a total catchment area of $\sim 194000 \mathrm{~km}^{2}$; the largest tributary, the Kagera River, contributes $\sim 30 \%$ of total river inflows (Sene and Plinston, 1994). Lake Victoria outflow to Lake Kyoga occurs at Jinja (Fig. 1).

Lake Kyoga (Fig. 1), located between the $32^{\circ} 10^{\prime}$ and $34^{\circ} 20^{\prime} \mathrm{E}$ longitudes and the $1^{\circ} 00^{\prime}$ and $2^{\circ} 00^{\prime} \mathrm{N}$ latitudes, has a mean area of $1720 \mathrm{~km}^{2}$ with an estimated mean volume of $12 \mathrm{~km}^{3}$ (Owor, 2010; UNEP, 2013). According to the recent global HydroSHEDS (Hydrological data and maps based on shuttle elevation derivatives at multiple scales) database, Lake Kyoga has a total surface area of $2729 \mathrm{~km}^{2}$ (Lehner

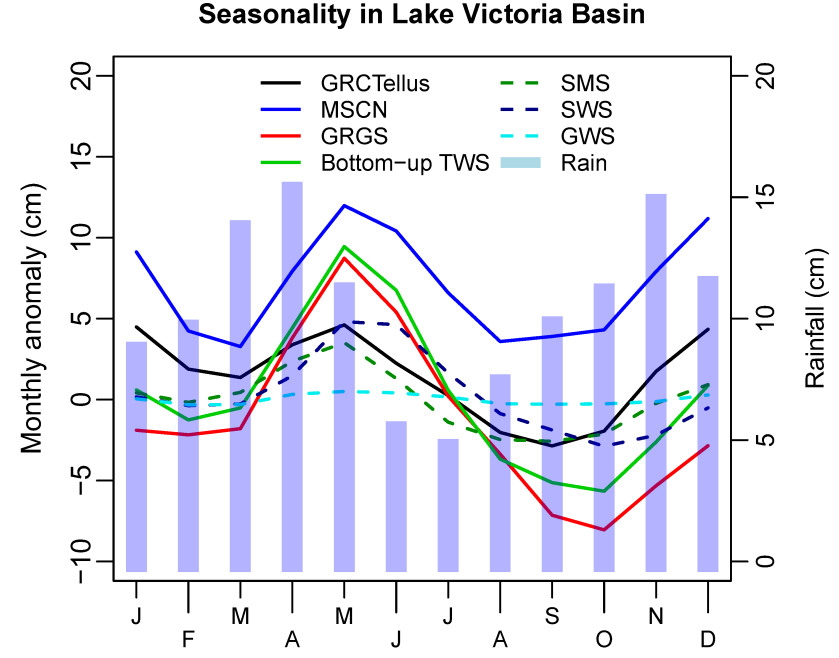

Figure 4. Seasonal pattern (monthly mean from January 2003 to December 2012) of TRMM-derived monthly rainfall, various GRACE-derived $\triangle$ TWS signals (GRCTellus: ensemble mean of CSR, JPL, and GFZ; GRGS and JPL-Mascons (MSCN) products), the bottom-up TWS, GLDAS LSM ensemble mean $\triangle$ SMS, in situ $\Delta S W S$, and a borehole-derived estimate of $\Delta \mathrm{GWS}$ over the Lake Victoria Basin.

et al., 2008). Lake Kyoga comprises lake-zone and throughflow conduit areas. The lake zone in Lake Kyoga is very shallow, with a mean depth of 3.5-4.5 m (Owor, 2010). Lake Kyoga has a through-flow channel (mean depth 7-9 m) where the main Victoria Nile River flows (Owor, 2010) and acts as a linear reservoir with the annual water balance predominantly governed by the discharge of the Victoria Nile from Lake Victoria. Whilst numerous rivers flow into Lake Kyoga (e.g. rivers Mpologoma, Awoja, Omunyal, Abalang, Olweny, Sezibwa, and Enget), the majority contributes a fraction of their former volume upon reaching the lake (Krishnamurthy and Ibrahim, 1973) due, in part, to evapotranspirative losses from fringe swamp areas $\left(4510 \mathrm{~km}^{2}\right)$ surrounding the lake (UNEP, 2013).

\subsection{Hydrogeological setting}

The Upper Nile Basin is underlain primarily by deeply weathered crystalline rock aquifer systems that have evolved through long-term, tectonically driven cycles of deep weathering and erosion (Taylor and Howard, 2000). Groundwater occurs within unconsolidated regoliths or "saprolite" and, below this, in fractured bedrock, known as "saprock". Bulk transmissivities of the saprolite and saprock aquifers are generally low (1-20 $\mathrm{m}^{2} \mathrm{~d}^{-1}$ ) (Taylor and Howard, 2000; Owor, 2010) and field estimates of the specific yield of the saprolite, the primary source of groundwater storage in these aquifer systems, are $2 \%$ based on pumping tests with tracers (Taylor et al., 2010) and magnetic resonance sounding experiments (Vouillamoz et al., 2014). Borehole yields are highly variable 
Table 1. Estimated areal extent $\left(\mathrm{km}^{2}\right)$ of the Lake Victoria Basin (LVB), the Lake Kyoga Basin (LKB), Lake Victoria, and Lake Kyoga.

\begin{tabular}{lrrr}
\hline Basin/lake & This study & UNEP (2013) & Awange et al. (2014) \\
& (HydroSHEDS database) & & \\
\hline Lake Victoria Basin & 256100 & 184000 & 258000 \\
Lake Victoria & 67220 & 68800 & - \\
Lake Kyoga Basin & 79270 & 75000 & 75000 \\
Lake Kyoga & 2730 & 1720 & - \\
\hline
\end{tabular}

but generally low $\left(0.5-20 \mathrm{~m}^{3} \mathrm{~h}^{-1}\right)$, yet are of critical importance to the provision of safe drinking water.

\subsection{An observed reduction in TWS in the LVB}

In 1954, the construction of the Nalubaale Dam (formerly Owen Falls Dam) at the outlet of Lake Victoria at Jinja transformed the lake into a controlled reservoir (Sene and Plinston, 1994). Operated as a run-of-river hydroelectric project to mimic pre-dam outflows, the "agreed curve" between Uganda and Egypt dictated dam releases that were controlled on a 10-day basis and generally adhered to, with compensatory discharge releases to minimize any departures, until the construction of the Kiira Dam at Jinja in 2002 (Sene and Plinston, 1994; Owor et al., 2011).

The combined discharge of the Nalubaale and Kiira dams enabled total dam releases (Fig. 2) to substantially exceed the agreed curve (Sutcliffe and Petersen, 2007), and between May 2004 and February 2006 the lake level dropped by $1.2 \mathrm{~m}$ (equivalent $\triangle$ SWS loss of $81 \mathrm{~km}^{3}$ ) (Owor et al., 2011). Mean annual releases were $1387 \mathrm{~m}^{3} \mathrm{~s}^{-1}(+162 \%$ of the agreed curve) in 2004 and $1114 \mathrm{~m}^{3} \mathrm{~s}^{-1}(+148 \%$ of the agreed curve) in 2005. Sharp reductions in dam releases in 2006 helped to arrest and reverse the lake-level decline, with lake levels stabilizing by early 2007 .

\section{Data and methods}

\subsection{Datasets}

We use publicly available time-series records of (1) GRACE TWS solutions from a number of data-processing strategies and dissemination centres including NASA's GRCTellus land solutions (RL05 for CSR, GFZ, version DSTvSCS1409, RL05.1 for JPL; version DSTvSCS1411, and JPL-Mascons solution, version RL05M_1.MSCNv01) as well as the French National Centre for Space Studies (CNES) GRGS solution (version GRGS RL03-v1); (2) NASA's Global Land Data Assimilation System (GLDAS) simulated soil moisture data from three global land-surface models (LSMs) (CLM, NOAH, VIC); and (3) monthly precipitation data from NASA's Tropical Rainfall Measuring Mission (TRMM) satellite mission. We also employ in situ observations of lake levels and groundwater levels from a network of river gauges and monitoring boreholes operated by the Ministry of Water and Environment in Entebbe (Uganda). Datasets are briefly described below.

\subsubsection{Delineation of basin study areas}

Delineation of the LVB and LKB was conducted in a geographic information system (GIS) environment under an ArcGIS (v.10.3.1) environment using the Hydrological Basins in Africa datasets derived from the HydroSHEDS database (available at http://www.hydrosheds.org/) (Lehner et al., 2006, 2008). Regional water bodies, including lakes Victoria and Kyoga (Fig. 1), were spatially defined by the Inland Water dataset available globally at country scale from DIVA-GIS (http://www.diva-gis.org/). Computed areas of the basins and lake surface areas are summarized in Table 1 along with previously estimated figures from other studies.

\subsubsection{GRACE-derived terrestrial water storage (TWS)}

Twin GRACE satellites provide monthly gravity variations interpretable as $\Delta$ TWS (Tapley et al., 2004) with an accuracy of $\sim 1.5 \mathrm{~cm}$ (equivalent water thickness or depth) when spatially averaged (Wahr et al., 2006). In this study, we apply five different monthly GRACE solutions for the period of January 2003 to December 2012: post-processed, gridded $\left(1^{\circ} \times 1^{\circ}\right)$ GRACE-TWS time-series records from three GRCTellus land solutions from CSR, JPL, and GFZ processing centres (available at http://grace.jpl.nasa.gov/data) (Swenson and Wahr, 2006; Landerer and Swenson, 2012), JPL-Mascons (Watkins et al., 2015; Wiese et al., 2015), and GRGS GRACE products (CNES/GRGS release RL03-v1) (Biancale et al., 2006).

GRCTellus land solutions are post-processed from two versions, RL05 and RL05.1 of spherical harmonics released by the University of Texas at Austin Centre for Space Research (CSR), the German Research Centre for Geosciences Potsdam (GFZ), and NASA's Jet Propulsion Laboratory (JPL) respectively. GRCTellus gridded datasets are available at a monthly time step at a spatial resolution of $1^{\circ} \times 1^{\circ}(\sim 111 \mathrm{~km}$ at the Equator $)$ though the actual spatial resolution of the GRACE footprint is $\sim 450 \mathrm{~km}$ or $\sim 200000 \mathrm{~km}^{2}$ (Scanlon et al., 2012). Post-processing of GRCTellus GRACE datasets primarily involve (i) removal of atmospheric pressure or mass changes based on 
the European Centre for Medium-Range Weather Forecasts (ECMWF) model; (ii) a glacial isostatic adjustment (GIA) correction based on a viscoelastic 3-D model of the Earth (A et al., 2013); and (iii) an application of a destriping filter plus a $300 \mathrm{~km}$ Gaussian to minimize the effect of correlated errors (i.e. destriping) manifested by $\mathrm{N}-\mathrm{S}$ elongated stripes on GRACE monthly maps. However, the use of a large spatial filter and truncation of spherical harmonics leads to energy removal, so scaling coefficients or factors are applied to the GRCTellus GRACE-derived TWS data in order to restore attenuated signals (Landerer and Swenson, 2012). Dimensionless scaling factors are provided as $1^{\circ} \times 1^{\circ}$ bins (see Fig. S1 in the Supplement) that are derived from the Community Land Model (CLM4.0) (Landerer and Swenson, 2012).

JPL-Mascons (version RL05M_1.MSCNv01) data processing also involves a glacial isostatic adjustment (GIA) correction based on a viscoelastic 3-D model of the Earth (A et al., 2013). JPL-Mascons applies no spatial filtering as JPL-RL05M directly relates inter-satellite range-rate data to mass concentration blocks or Mascons to estimate global monthly gravity fields in terms of equal area $3^{\circ} \times 3^{\circ}$ mass concentration functions to minimize measurement errors. The use of Mascons and the special processing result in better signal-to-noise ratios of the Mascon fields compared to the conventional spherical harmonic solutions (Watkins et al., 2015). For convenience, gridded Mascon fields are provided at a spatial sampling of $0.5^{\circ}$ in both latitude and longitude ( $\sim 56 \mathrm{~km}$ at the Equator). As with GRCTellus GRACE datasets, the neighbouring grid cells are not "independent" of each other and cannot be interpreted individually at the $1^{\circ}$ or $0.5^{\circ}$ grid scale (Watkins et al., 2015). Similar to GRCTellus GRACE (CSR, JPL, GFZ) products, dimensionless scaling factors are provided as $0.5^{\circ} \times 0.5^{\circ}$ bins (see Fig. S2) that are also derived from the Community Land Model (CLM4.0) (Wiese et al., 2016). The gain factors or scaling coefficients are multiplicative factors that minimize the difference between the smoothed and unfiltered monthly $\triangle$ TWS variations from "actual" land hydrology at a given geographical location (Wiese et al., 2016).

GRGS/CNES GRACE monthly products (version RL03v1) are processed and made publicly available (http://grgs. obs-mip.fr/grace) by the French Government space agency, National Centre for Space Studies or Centre National d' Études Spatiales (CNES). The post-processing of GRGS data involves taking into account of gravitational variations such as Earth tides, ocean tides, and 3-D gravitational potential of the atmosphere and ocean masses (Bruinsma et al., 2010). The remaining signals for time-varying gravity fields therefore represent changes in terrestrial hydrology including snow cover, baroclinic oceanic signals and effects of postglacial rebound (Biancale et al., 2006; Lemoine et al., 2007). Further details on the Earth's mean gravity-field models can be found on the official website of GRGS/LAGEOS (http: //grgs.obs-mip.fr/grace/).
GRACE satellites were launched in 2002 to map the variations in Earth's gravity field over its 5-year lifetime, but both satellites are still in operation even after more than 14 years. However, active battery management since 2011 has led the GRACE satellites to be switched off every 5-6 months for 4-5-week durations in order to extend its total lifespan (Tapley et al., 2015). As a result, GRACE $\triangle$ TWS time-series data have some missing records that are linearly interpolated (Shamsudduha et al., 2012). In this study, we derive $\Delta$ TWS time-series data as equivalent water depth $\left(\mathrm{cm}\right.$ of $\left.\mathrm{H}_{2} \mathrm{O}\right)$ using the basin boundaries (GIS shapefiles) for masking the $1^{\circ} \times 1^{\circ}$ grids.

\subsubsection{Rainfall data}

We apply the Tropical Rainfall Measuring Mission (TRMM) (Huffman et al., 2007) monthly product (3B43 version 7) for the period of January 2003 to December 2012 at $0.25^{\circ} \times$ $0.25^{\circ}$ spatial resolution and aggregate to $1^{\circ} \times 1^{\circ}$ grids over the LVB and LKB. The general climatology of the Upper Nile Basin is represented by a long-term (2003-2012) mean annual rainfall (Fig. 3) and seasonal rainfall pattern (Fig. 4). TRMM rainfall measurements show a good agreement with limited observational precipitation records (Awange et al., 2008, 2014).

\subsubsection{Soil moisture storage (SMS)}

NASA's Global Land Data Assimilation System (GLDAS) is an uncoupled land-surface modelling system that drives multiple land surface models (GLDAS LSMs: CLM, NOAH, VIC and MOSAIC) globally at high spatial and temporal resolutions (3-hourly to monthly at $0.25^{\circ} \times 0.25^{\circ}$ grid resolution) and produces model results in near-real time (Rodell et al., 2004). These LSMs provide a number of output variables which include soil moisture storage (SMS). Similar to the approach applied in the analysis of GRACE-derived $\triangle \mathrm{TWS}$ analysis in the Bengal Basin (Shamsudduha et al., 2012), we apply simulated monthly $\triangle$ SMS records at a spatial resolution of $1^{\circ} \times 1^{\circ}$ from three GLDAS LSMs: the Community Land Model (CLM, version 2) (Dai et al., 2003), NOAH (version 2.7.1) (Ek et al., 2003) and the Variable Infiltration Capacity (VIC) model (version 2.7.1) (Liang et al., 2003). The respective depths of modelled soil profiles are 3.4, 2.0, and $1.9 \mathrm{~m}$ in CLM (10 vertical layers), NOAH (4 vertical layers), and VIC (version 1.0) (3 vertical layers). Because of the absence of in situ soil moisture data in the study areas, we apply an ensemble mean of the aforementioned three LSMsderived simulated $\triangle \mathrm{SMS}$ time-series records (see Figs. 5 and 6) in order to disaggregate GRACE $\triangle \mathrm{TWS}$ signals in the LVB and LKB.

\subsubsection{Surface water storage (SWS)}

Daily time series of $\triangle \mathrm{SWS}$ are computed from in situ (gauged) lake-level observations at Jinja for Lake Victoria 

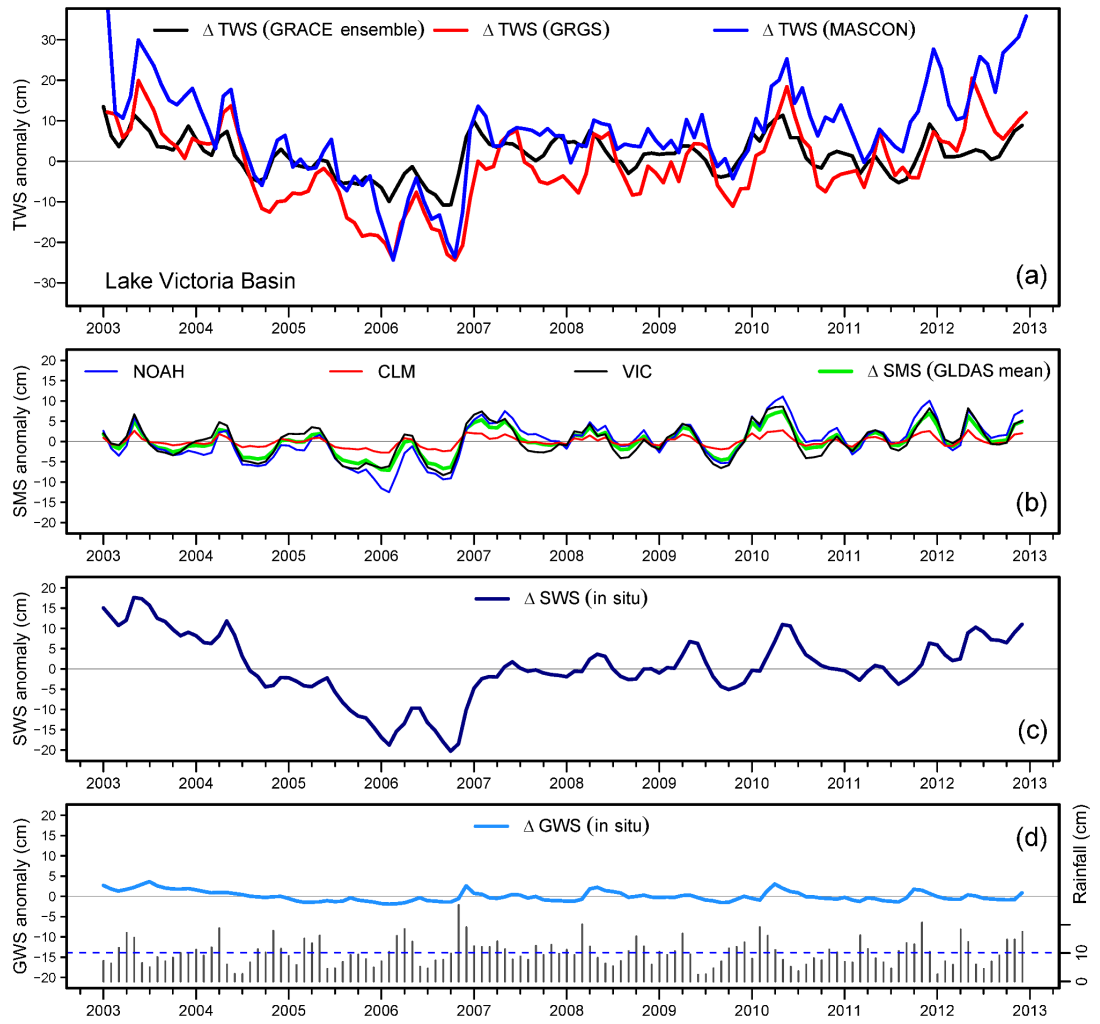

Figure 5. Monthly time-series datasets for the LVB from January 2003 to December 2012: (a) GRCTellus GRACE-derived $\Delta$ TWS (ensemble mean of CSR, GFZ, and JPL), GRGS and JPL-Mascons $\triangle$ TWS time-series data; (b) GLDAS-derived $\triangle$ SMS (individual signals as well as an ensemble mean of NOAH, CLM, and VIC); (c) lake-level-derived $\Delta$ SWS; and (d) borehole-derived $\Delta$ GWS time-series data. Note that monthly rainfall records derived from TRMM satellite are plotted on panel (d) where the dashed horizontal line represents the mean monthly rainfall for the period of January 2003 to December 2012.

and Bugondo for Lake Kyoga (Figs. 1 and 2) compiled by the Ugandan Ministry of Water and Environment (Directorate of Water Resources Management). Mean monthly anomalies for the period of January 2003-December 2012 were computed as an equivalent water depth using Eq. (2). Missing data in the time series (2003-2012) records are linearly interpolated. For instance, in the case of monthly $\Delta$ SWS derived from Lake Kyoga water levels, there is one missing record (December 2005).

$\Delta \mathrm{SWS}=\Delta$ Lake level $\cdot\left(\frac{\text { Lake area }}{\text { Total basin area }}\right)$

\subsubsection{Groundwater storage (GWS) from borehole observations}

Time series of $\Delta$ GWS are constructed from in situ piezometric records from 6 monitoring wells located in the LVB and LKB where near-continuous, daily observations exist from January 2003 to December 2012 and have been compiled by the Ugandan Ministry of Water and Environment (Directorate of Water Resources Management) (Owor et al., 2009,
2011). Monitoring boreholes were installed into weathered, crystalline rock aquifers that underlie much of the LVB and LKB, and are remote from local abstraction. As such, they represent variations in groundwater storage influenced primarily by climate variability. Mean monthly anomalies of $\Delta$ GWS, standardized to mean records from January 2003 to December 2012, were derived from near-continuous, daily observations at Entebbe, Rakai, and Nkokonjeru for the LVB and at Apac, Pallisa, and Soroti for the LKB (Figs. 1 and S3; Table 2). In the Lake Kyoga Basin, piezometric records from three sites show consistency in the seasonality and amplitude of groundwater storage changes plotted as monthly groundwater-level anomalies relative to the mean for the period from January 2003 to December 2012. In the Lake Victoria Basin, groundwater-level records from two sites (Entebbe, Nkokonjeru) are similar in their phase and amplitude, and are influenced by changes in the level of Lake Victoria as demonstrated by Owor et al. (2011). The groundwater-level record from Rakai represents local semi-arid conditions that exist within catchment areas (e.g. the Ruizi River) draining to the western shore of Lake Victoria in Uganda. Although there are differences in the phase of groundwater-level fluctuations between the semi-arid site at Rakai and both Entebbe 

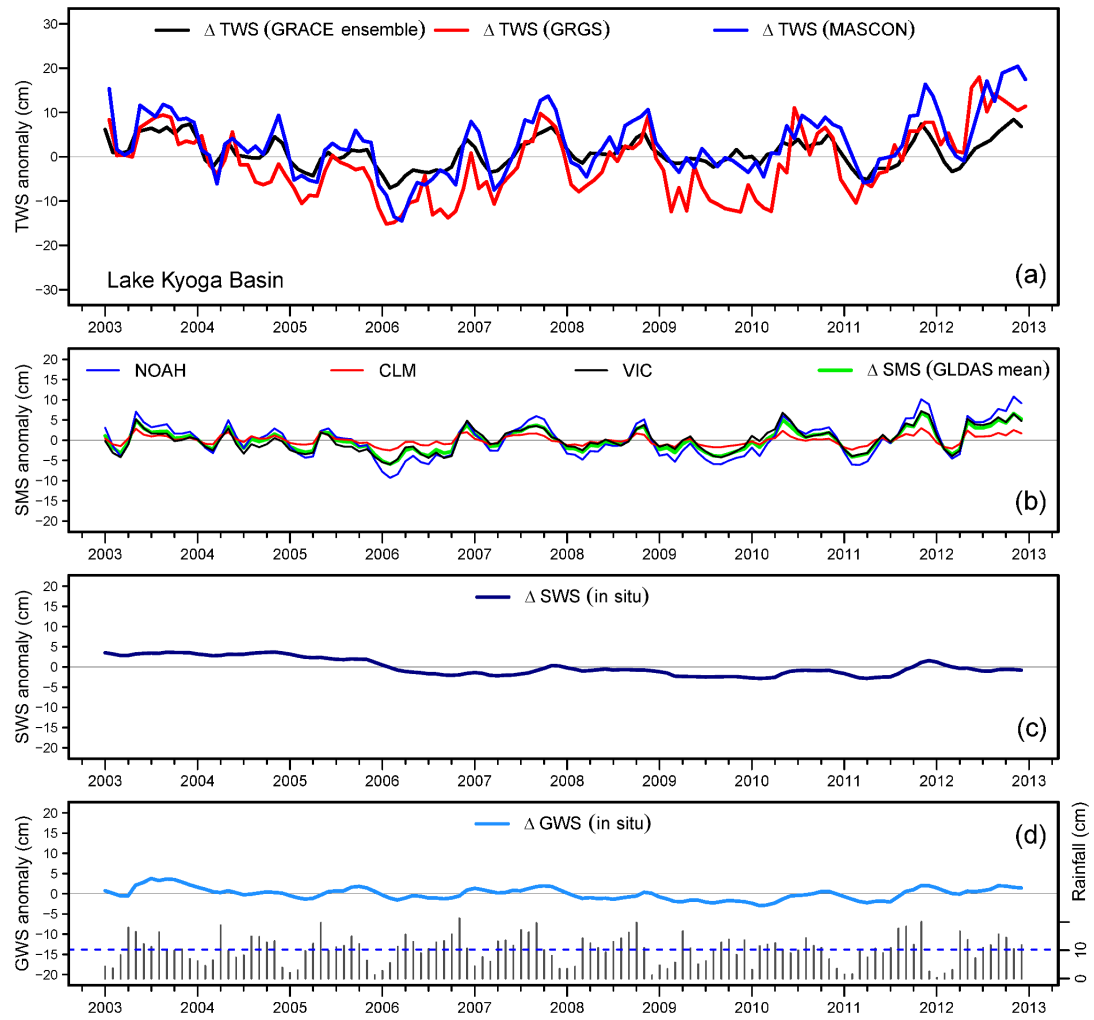

Figure 6. Monthly time-series datasets for the Lake Kyoga Basin (LKB) from January 2003 to December 2012: (a) GRCTellus GRACEderived $\triangle$ TWS (ensemble mean of CSR, GFZ, and JPL), GRGS, and JPL-Mascons $\triangle$ TWS time-series data; (b) GLDAS-derived $\Delta$ SMS (individual signals as well as an ensemble mean of NOAH, CLM, and VIC); (c) lake-level-derived $\Delta$ SWS; and (d) borehole-derived $\Delta$ GWS time-series data. Note that monthly rainfall records derived from the TRMM satellite are plotted in panel (d) where the dashed horizontal line represents the mean monthly rainfall for the period of January 2003 to December 2012.

Table 2. Details of groundwater and lake-level monitoring stations located in the Lake Victoria Basin and Lake Kyoga Basin.

\begin{tabular}{lllrrr}
\hline Monitoring station & Basin & Parameter & Longitude & Latitude & Depth (m b.g.1.) \\
\hline Apac & LKB & Groundwater level & 32.50 & 1.99 & 15.0 \\
Pallisa & LKB & Groundwater level & 33.69 & 1.20 & 46.2 \\
Soroti & LKB & Groundwater level & 33.63 & 1.69 & 66.0 \\
Bugondo & LKB & Lake level & 33.20 & 0.45 & - \\
Entebbe & LVB & Groundwater level & 32.47 & 0.04 & 48.0 \\
Rakai & LVB & Groundwater level & 31.40 & -0.69 & 53.0 \\
Nkokonjeru & LVB & Groundwater level & 32.91 & 0.24 & 30.0 \\
Jinja & LVB & Lake level & 33.23 & 1.59 & - \\
\hline
\end{tabular}

and Nkokonjeru (as well as the three sites in the Lake Kyoga Basin), annual amplitudes are similar.

The groundwater-level time series data are a sub-set of the total number of available monitoring-well records in the LVB and LKB and selected on the basis of (i) the completeness and quality of the records from 2003 to 2012, and (ii) rigorous review of groundwater-level records conducted at a dedicated workshop at the Ministry of Water \& Environment in January 2013. These records represent shallow groundwater-level observations within the saprolite that is dynamically connected to surface waters (Owor et al., 2011). Long time-series records of groundwater levels over the period from 2003 to 2012 from western Kenya, northern Tanzania, Rwanda, and Burundi have not been identified despite intensive investigations carried out by The Chronicles Consortium. ${ }^{1}$ The partial spatial coverage in quality-controlled piezometry, especially for the LVB, represents an important limitation in our analysis.

\footnotetext{
${ }^{1}$ The Chronicles Consortium: https://www.un-igrac.org/ special-project/chronicles-consortium
} 
Mean monthly anomalies were translated into an equivalent water depth (Eq. 3) by applying a range of specific yield $\left(S_{y}\right)$ values (1-6\% with an average of $3 \%$ ), although estimates of $S_{y}$ in hard-rock environments are observed to vary from $<2$ to $8 \%$ (Taylor et al., 2010, 2013; Vouillamoz et al., 2014) using Eq. (3). Missing data in the time series were linearly interpolated. In the case of monthly $\Delta \mathrm{GWS}$ that were derived from borehole $(n=6)$ observations, missing records range from 1 to 9 months (120 months in 20032012), with three boreholes (Soroti, Rakai, and Nkonkonjero) with time-series records ending in June-July 2010.

$\Delta \mathrm{GWS}=\Delta h \cdot S_{y} \cdot\left(\frac{\text { Land area }}{\text { Total basin area }}\right)$

\subsection{Methodologies}

\subsubsection{GRACE $\triangle T W S$ estimation}

First, the $1^{\circ} \times 1^{\circ}$ gridded monthly anomalies of GRACEderived $\triangle$ TWS and GLDAS LSM-derived $\triangle$ SMS are masked over the area of the LVB and LKB. GRACE $\triangle$ TWS along with GLDAS $\triangle$ SMS are extracted for the marked $1^{\circ} \times 1^{\circ}$ grid cells for the LVB and LKB and the grid values are spatially aggregated to form time series of monthly anomalies $\triangle$ TWS and $\triangle$ SMS.

GRCTellus GRACE $\triangle$ TWS gridded data are scaled using dimensionless, gridded scaling factors. Several GRACE studies (Rodell et al., 2009; Sun et al., 2010; Shamsudduha et al., 2012) have applied scaling factors in three different ways: (1) a single scaling factor based on regionally averaged time series, (2) spatially distributed or gridded scaling factors based on time series at each grid point, and (3) gridded-gain factors estimated as a function of time or of temporal frequency (Landerer and Swenson, 2012; Long et al., 2015). In this study, we apply a spatially distributed scaling approach (method 2 above) to generate basin-averaged $\Delta$ TWS time-series records for GRCTellus (CSR, JPL, GFZ) products. Scaling factors provided at $1^{\circ} \times 1^{\circ}$ grids are applied to each corresponding GRACE $\triangle$ TWS grid for NASA's GRCTellus products in order to restore attenuated signals during the post-processing (Landerer and Swenson, 2012) using Eq. (4). Similarly, provided scaling factors are applied to JPL-Mascons $\Delta$ TWS time-series data but at $0.5^{\circ} \times 0.5^{\circ}$ grid resolution. No scaling factors were applied to GRGS GRACE $\triangle$ TWS as the monthly gravity solutions have already been stabilized during their generation process.

$g^{1}(x, y, t)=g(x, y, t) \cdot s(x, y)$

Here, $g^{1}(x, y, t)$ represents each un-scaled grid where $x$ represents longitude, $y$ represents latitude, $t$ represents time (month), and $s(x, y)$ is the corresponding scaling factor.

For the three GRCTellus gridded products (i.e. CSR, GFZ, and JPL solutions), we apply an ensemble mean of scaled GRACE $\triangle T W S$ as our exploratory analyses reveal that
$\Delta$ TWS time-series records over the Lake Victoria Basin are highly correlated $(r>0.95, p$ value $<0.001)$ with each other. Additionally, a small (ranges from 1.3 to $1.9 \mathrm{~cm}$ ) root mean square error (RMSE) among the GRACE $\triangle$ TWS datasets suggests substantial similarities in phase and amplitude.

\subsubsection{Estimation of $\Delta G W S$ from GRACE}

Estimation of groundwater storage changes $(\triangle \mathrm{GWS})$ from GRACE measurements is conducted using Eq. (5) in which $\Delta \mathrm{TWS}_{t}$ is derived from gridded GRACE products (spatially scaled $\triangle$ TWS for GRCTellus and JPL-Mascons but unscaled $\Delta$ TWS for GRGS), $\Delta$ SMS $_{t}$ is an ensemble mean of three GLDAS LSMs (CLM, NOAH, VIC), and $\Delta \mathrm{SWS}_{t}$ is areaweighted, in situ surface water storage estimated from lakelevel records using Eq. (2).

$\Delta \mathrm{GWS}_{t}=\Delta \mathrm{TWS}_{t}-\left(\Delta \mathrm{SWS}_{t}+\Delta \mathrm{SMS}_{t}\right)$

\subsubsection{Reconciliation of GRACE $\triangle$ TWS disaggregation}

Reconciling GRACE-derived TWS with ground-based observations is limited by the paucity of in situ observations of SMS, SWS, and GWS in many environments. In addition, direct comparisons between in situ observations of $\triangle \mathrm{SMS}, \Delta \mathrm{SWS}$, and $\triangle \mathrm{GWS}$ and gridded GRACE $\triangle \mathrm{TWS}$ anomalies are complicated by substantial differences in spatial scales, which need to be considered prior to analysis (Becker et al., 2010). For example, individual groundwaterlevel monitoring boreholes may represent, depending on borehole depth, a sensing area of several tens of square kilometres (Burgess et al., 2017), whereas the typical GRACE footprint is $\sim 200000 \mathrm{~km}^{2}$. The disaggregation of GRACE $\triangle$ TWS into individual water stores can also propagate errors to disaggregated components. Here, we construct "in situ" or "bottom-up" $\Delta$ TWS (i.e. combined signals of $\Delta$ SMS, $\Delta \mathrm{SWS}$, and $\Delta \mathrm{GWS}$ ) for the Lake Victoria Basin and attempt to reconcile with GRACE-derived $\triangle$ TWS. One feature of GRACE $\triangle$ TWS among the three solutions we apply in this study is the considerable variation in annual amplitudes that exist over the period of 2003-2012.

In addition, for the GRCTellus products, we conduct unconventional scaling experiments, outlined below in an attempt to reconcile satellite and in situ measures and to shed light on the uncertainty in $\triangle$ TWS amplitudes of the GRCTellus GRACE products. The $\triangle$ TWS signals in CSR, JPL, and GFZ products are greatly attenuated due to spatial smoothing and the amplitude is substantially smaller compared to JPL-Mascons and GRGS products. In the first scaling experiment, we apply an additional, basin-averaged, multiplicative scaling factor to $\triangle$ TWS ranging from 1.1 to 2.0 and employ RMSE to assess their relative performance. With reference to the GRCTellus GRACE $\triangle$ TWS and bottom-up $\Delta$ TWS relationship, the scaling factor producing the lowest RMSE between the two time series is employed. Secondly, it is ob- 
served that, in the LVB, $\triangle \mathrm{SWS}$ is the largest contributor, representing $\sim 50 \%$ variance in the in situ or bottom-up $\Delta$ TWS time-series signal. GRACE $\triangle$ TWS analyses commonly apply the same scaling factor as $\triangle$ TWS to all other individual components (Landerer and Swenson, 2012). Therefore, under the scaling experiment, we apply to in situ $\triangle$ SWS spatially averaged scaling factors representative of (i) Lake Victoria and its surrounding grid cells (experiment 1: $s=0.71$; range $0.02-1.5$ ), and (ii) the open-water surface of Lake Victoria without surrounding grid cells (experiment 2: $s=0.11$; range 0.02-0.30). Furthermore, we find that the amplitude of monthly anomalies of $\Delta$ SWS $+\Delta$ SMS combined substantially exceed $\Delta$ TWS (see Fig. S4), particularly for the GRCTellus GRACE $\triangle$ TWS signal that is greatly smoothed due to filtering. This discrepancy is pronounced over the period of 2003-2006, and when applied to estimate GRACEderived $\triangle \mathrm{GWS}$, produces steep, rising trends in the estimated $\Delta$ GWS (i.e. GRACE $\Delta$ TWS $-(\Delta$ SWS $+\Delta$ SMS $)$ ), whereas borehole observations of groundwater levels show a declining trend and are of much a lower amplitude over the same period.

\section{Results}

Monthly time-series records (January 2003-December 2012) are presented in Figs. 5 and 6 respectively for the LVB and LKB of (a) GRACE $\triangle$ TWS from GRCTellus GRACE $\triangle$ TWS (ensemble mean of CSR, GFZ, and JPL solutions), GRGS and JPL-Mascons, (b) GLDAS land-surface models (LSMs) derived $\triangle$ SMS (ensemble mean of three LSMs: $\mathrm{NOAH}, \mathrm{CLM}, \mathrm{VIC}$ ), (c) in situ $\triangle \mathrm{SWS}$ from lake levels records, and (d) in situ $\triangle$ GWS borehole observations. Monthly rainfall derived from TRMM satellite observations over the same period are shown on the bottom panel (d). Time-series records of all $\Delta$ TWS components and rainfall are aggregated for the LVB to represent the average seasonal (monthly) pattern of each signal (Fig. 4) that shows an obvious lag $(\sim 1$ month) between peak rainfall (March-April) and $\triangle$ TWS and its individual components.

Mean annual (2003-2012) amplitudes of various GRACEderived $\Delta$ TWS signals, bottom-up $\Delta$ TWS, ensemble mean of simulated $\Delta \mathrm{SMS}$, in situ $\Delta \mathrm{SWS}$, and $\Delta \mathrm{GWS}$ time-series records (Figs. 5 and 6) are presented (see Table S1 in the Supplement) for both the LVB and LKB. The mean annual amplitude of GRACE $\triangle$ TWS ranges from 11 to $21 \mathrm{~cm}$ among GRCTellus, GRGS, and JPL-Mascons GRACE products in the LVB, and from 8.4 to 16.4 respectively in the LKB. The mean annual amplitude of in situ $\triangle \mathrm{SWS}$ is much greater $(14.8 \mathrm{~cm})$ in the LVB than in the LKB $(3.8 \mathrm{~cm})$. The GLDAS LSM-derived ensemble mean $\triangle$ SMS amplitude in the LVB is 7.9 and $7.3 \mathrm{~cm}$ in the LKB. The standard deviation in $\triangle \mathrm{SMS}$ varies substantially in the $\operatorname{LVB}(1.2,4.2$, and $2.9 \mathrm{~cm})$ and LKB $(1.3,4.7$, and $4.0 \mathrm{~cm})$ for the CLM, NOAH, and VIC models respectively. The mean annual amplitude of in situ $\Delta$ GWS ranges from $4.4 \mathrm{~cm}$ (LVB) to $3.5 \mathrm{~cm}$ (LKB).

Time-series correlation (Pearson) analysis over various periods of interests (decadal: 2003-2012; well-constrained SWS reduction or the period of the unintended experiment: 2003-2006; controlled dam operation: 2007-2012) reveals that GRACE-derived $\triangle$ TWS signals are strongly correlated in both the LVB and LKB (see Figs. S5-S10). For example, in the LVB, in situ $\triangle$ SWS shows a statistically significant $(p$ value $<0.001)$ strong correlation $(r=0.77-0.92)$ with all GRACE- $\Delta$ TWS time-series (2003-2012) records. Similarly, simulated $\triangle \mathrm{SMS}$ shows statistically significant ( $p$ value $<0.001)$ strong correlation $(r=0.70-0.78)$ with $\Delta$ TWS time-series records. In contrast, in situ $\Delta \mathrm{GWS}$ shows statistically significant ( $p$ value $<0.001$ ) but moderate correlation $(r=0.63-0.69)$ with $\Delta$ TWS time-series records. Correlation among the variables shows similar statistically significant ( $p$ value $<0.001$ ) but wide-ranging associations for the periods of the unintended experiment (2003-2006) and controlled dam operation (2007-2012). In the LKB, however, correlation among in situ $\triangle \mathrm{SWS}$ and GRACE $\triangle$ TWS time-series records is statistically significant $(p$ value $<0.05$ ) but poor in correlation strength $(r=0.22-0.34)$. In situ $\Delta$ GWS shows statistically significant $(p$ value $<0.001)$ strong correlation $(r=0.64-0.69)$ with GRACE $\triangle$ TWS time-series records.

Time-series records of all three $\triangle T W S$ from five GRACE products and bottom-up $\triangle$ TWS time-series records in both the LVB and LKB are shown in Fig. 7; results of temporal trends are summarized in Table 3. Statistically significant ( $p$ value $<0.05$ ) declining trends $\left(-4.1\right.$ to $-11.0 \mathrm{~cm} \mathrm{yr}^{-1}$ in the LVB; -2.1 to $-4.6 \mathrm{~cm} \mathrm{yr}^{-1}$ in the LKB) are consistently observed during the period of 2003-2006. Trends are all positive in GRACE $\triangle$ TWS and bottom-up $\triangle$ TWS time-series records over the recent period of controlled dam operation (2007-2012) in both the LVB and LKB. The overall, decadal (2003-2012) trends are slightly rising $\left(0.04-1.00 \mathrm{~cm} \mathrm{yr}^{-1}\right)$ in the LVB but nearly stable $\left(-0.01 \mathrm{~cm} \mathrm{yr}^{-1}\right)$ in GRCTellus $\triangle$ TWS and slightly declining $\left(-0.56 \mathrm{~cm} \mathrm{yr}^{-1}\right)$ in bottomup $\triangle$ TWS over the LKB. In addition, short-term volumetric trends (2003-2006) in GRACE and bottom-up $\triangle$ TWS as well as simulated $\triangle$ SMS and in situ $\triangle$ SWS are declining whereas in situ $\triangle$ GWS and rainfall anomalies show slightly rising trends over the same period in the LVB (see Figs. S11$\mathrm{S} 12)$. Similar trends are reported in various signals over the LKB, but magnitudes are much smaller compared to that of the LVB, which is 3 times larger in size than the LKB. Volumetric declines in $\triangle$ TWS in the LVB for the period 2003-2006 are: $83 \mathrm{~km}^{3}$ (bottom-up), $80 \mathrm{~km}^{3}$ (JPL-Mascons), $69 \mathrm{~km}^{3}$ (GRGS) and $31 \mathrm{~km}^{3}$ (GRCTellus ensemble mean of CSR, JPL and GFZ products).

Linear regression reveals that the association between GRACE-derived $\triangle$ TWS and bottom-up $\triangle$ TWS is stronger in the LVB $\left(R^{2}=0.75-0.90\right)$ than in the LKB $\left(R^{2}=0.56-\right.$ 0.62 ) (see Table S1). GRACE $\triangle$ TWS is unable to explain 
Table 3. Linear trends $\left(\mathrm{cm} \mathrm{yr}^{-1}\right)$ in GRACE $\Delta$ TWS and bottom-up $\Delta$ TWS in the Lake Victoria Basin and Lake Kyoga Basin over various time periods (statistically significant trends; $p$ values $<0.05$ are marked by an asterisk).

\begin{tabular}{lrrrr}
\hline Period & GRACE ensemble & GRGS & JPL-Mascons & Bottom-up TWS \\
\hline \multicolumn{5}{c}{ Lake Victoria Basin (LVB) } \\
\hline $2003-2006$ & $-4.10^{*}$ & $-9.00^{*}$ & $-10.0^{*}$ & $-11.00^{*}$ \\
$2007-2012$ & -0.31 & $1.50^{*}$ & $2.70^{*}$ & $1.10^{*}$ \\
$2003-2012$ & 0.04 & 0.58 & $1.00^{*}$ & 0.54 \\
\hline \multicolumn{6}{c}{} \\
\hline $2003-2006$ & Lake Kyoga Basin (LKB) \\
$2007-2012$ & $-2.10^{*}$ & $-4.60^{*}$ & $-3.50^{*}$ & $-2.80^{*}$ \\
$2003-2012$ & 0.22 & $2.00^{*}$ & $1.50^{*}$ & 0.48 \\
\hline
\end{tabular}
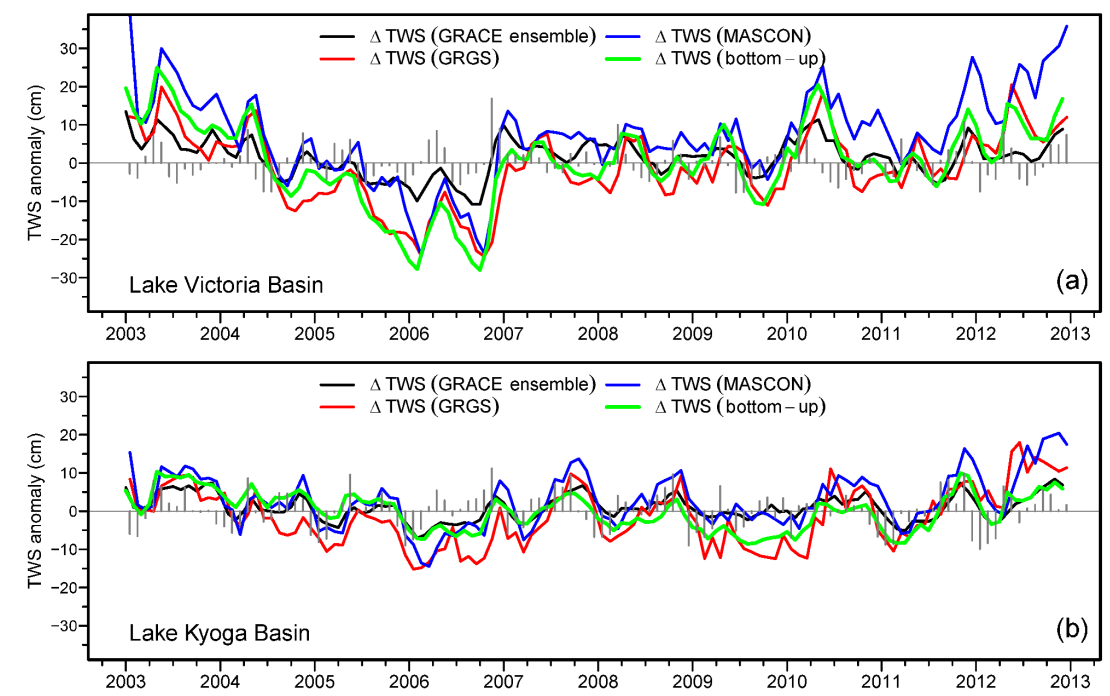

Figure 7. Comparison among time-series records of $\triangle$ TWS from GRCTellus (ensemble mean of CSR, GFZ, and JPL), GRGS and JPLMascons GRACE products and bottom-up $\triangle$ TWS for the LVB (a), and the LKB (b) for the period of January 2003 to December 2012 . The vertical grey lines represent monthly rainfall anomalies in the LVB and LKB.

natural variability in bottom-up $\triangle$ TWS in the LKB, though this may be explained by the fact that SWS in Lake Kyoga is influenced by dam releases from the LVB. Multiple linear regression and the analysis of variance (ANOVA) reveal that the relative proportion of variability in the bottomup $\Delta$ TWS time-series record can be explained by $\Delta$ SWS (92.6\%), $\Delta$ SMS $(6.5 \%)$, and $\Delta$ GWS $(0.66 \%)$ in the LVB; and by $47.9,48.5$, and $3.6 \%$ respectively in the LKB. These results are indicative only as these percentages can be biased by the presence of strong correlation among variables and the order of these variables listed as predictors in the multiple linear regression models.

Disaggregation of $\triangle$ GWS from GRACE $\triangle$ TWS timeseries record from each product has been carefully considered and estimated following Eq. (5). No further additional scaling factors, as described in the "scaling experiment" section (see results of scaling experiment in
Fig. S13) are applied in the final disaggregation of $\Delta \mathrm{GWS}$ from GRACE $\triangle$ TWS signals. Results of Pearson correlation analysis of the time-series record (2003-2012) of in situ $\triangle$ GWS in the LVB show statistically insignificant and poor correlation $(r=0.11, p$ value $=0.25)$ to JPLMascons and an inverse correlation with both the ensemble GRCTellus $(r=-0.55, p$ value $<0.001)$ and GRGS $(r=-0.27, p$ value $=0.003)$ GRACE-derived estimates of $\Delta$ GWS (Fig. 8). In contrast, in the LKB, in situ $\Delta$ GWS time-series record shows statistically significant but weak correlations to JPL-Mascons $(r=0.34, p$ value $<0.001)$ and GRGS $(r=0.39, p$ value $<0.001)$ GRACE-derived $\Delta$ GWS but shows an inverse correlation $(r=-0.21, p$ value $=0.02)$ to GRCTellus $\triangle$ GWS (see Fig. S14). Furthermore, RMSE among various GRACE-derived estimates of $\triangle \mathrm{GWS}$ and in situ $\triangle$ GWS ranges from $7.2 \mathrm{~cm}$ (GRACE ensemble), $3.8 \mathrm{~cm}$ (GRGS) to $8.2 \mathrm{~cm}$ (JPL-Mascons) in the LVB, and from 


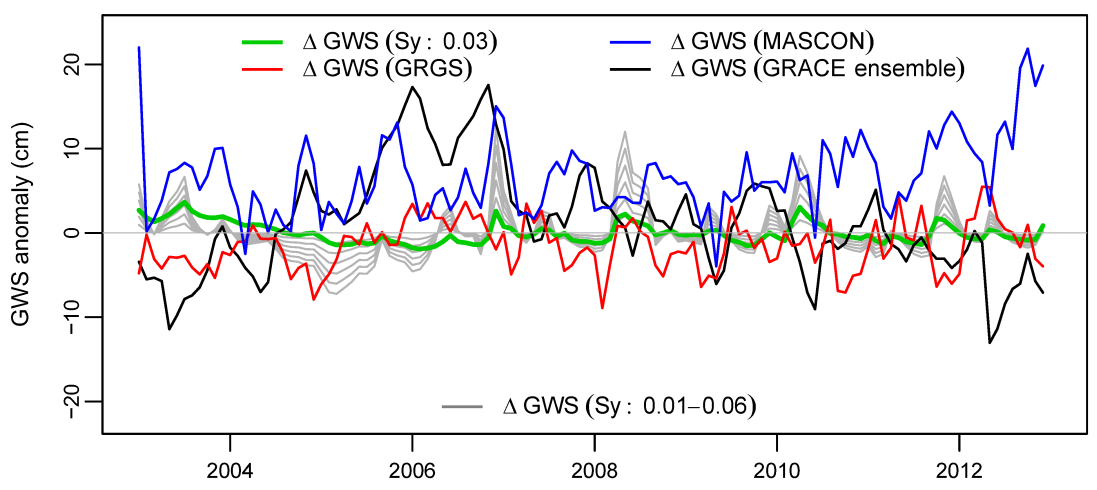

Figure 8. Estimates of in situ $\triangle \mathrm{GWS}$ and GRACE-derived $\triangle \mathrm{GWS}$ time-series records (January 2003 to December 2012) in the LVB show substantial variations among themselves. An ensemble mean $\triangle$ SMS (three GLDAS LSMs: CLM, NOAH, and VIC) and an unscaled $\triangle$ SWS are applied in the disaggregation of $\triangle \mathrm{GWS}$ using the GRCTellus GRACE (ensemble mean of CSR, GFZ, and JPL) and JPL-Mascons products.

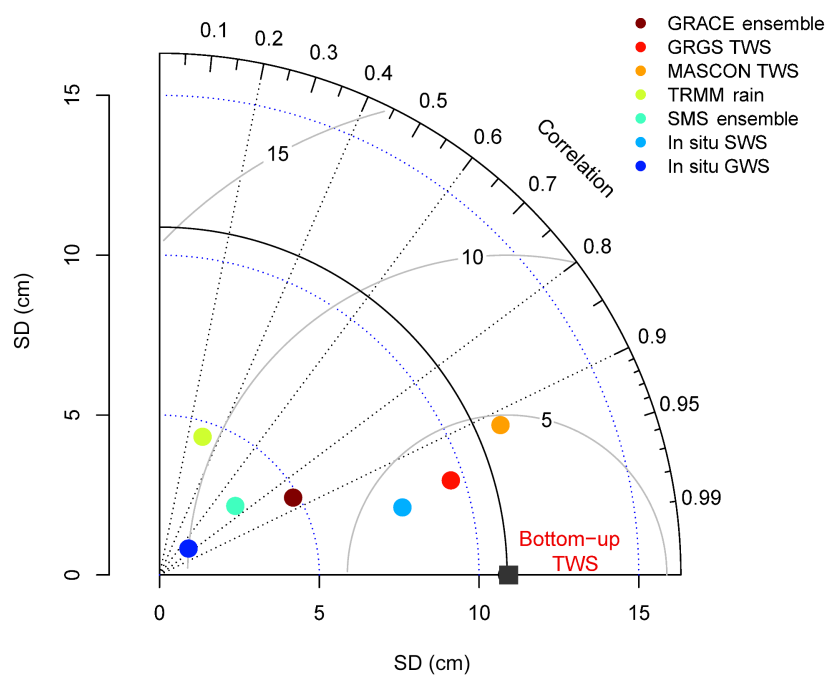

Figure 9. Taylor diagram shows strength of statistical association, variability in amplitudes of time-series records and agreement among the reference data, bottom-up $\triangle$ TWS and GRCTellus GRACE-derived $\triangle$ TWS (ensemble mean of CSR, GFZ, and JPL, GRGS and JPL-Mascons $\triangle$ TWS time-series records), simulated $\triangle$ SMS (ensemble mean of NOAH, CLM and VIC), in situ $\triangle$ SWS, and in situ $\triangle$ GWS over the LVB. The solid arcs around the reference point (black square) indicate centred root mean square (RMS) differences among bottom-up $\Delta$ TWS and other variables, and the dashed arcs from the origin of the diagram indicate variability in time-series records. Data for the LVB are only shown in this diagram.

$3.2 \mathrm{~cm}$ (GRACE ensemble), $5.3 \mathrm{~cm}$ (GRGS) to $5.4 \mathrm{~cm}$ (JPLMascons) in the LKB.

\section{Discussion}

We apply five different gridded GRACE products (GRCTellus - CSR, JPL, and GFZ; GRGS and JPL-Mascons) to test $\triangle$ TWS signals for the Lake Victoria Basin (LVB) comprising a large and accurately observed reduction $\left(83 \mathrm{~km}^{3}\right)$ in $\triangle$ TWS from 2003 to 2006. Our analysis reveals that all GRACE products capture this substantial reduction in terrestrial water mass, but the magnitude of GRACE $\triangle$ TWS among GRACE products varies substantially. For example, GRCTellus underrepresents greatly (63\%) the reduction of $83 \mathrm{~km}^{3}$ in bottom-up $\triangle$ TWS, whereas GRGS and JPLMascons GRACE products underrepresent this by 17 and $4 \%$ respectively. Previous studies in the Upper Nile Basin have relied upon a single GRACE product such as GRCTellus CSR (Nanteza et al., 2016) and GFZ (version (RL04) (Awange et al., 2014) without considering uncertainty in the seasonal amplitude of TWS associated with the processing of different GRACE products. Over a longer period (20032012) in the Upper Nile Basin, all GRACE products correlate well with bottom-up $\triangle$ TWS but, similar to the unintended experiment, variability in amplitude is considerable (Fig. 9). The average (2003-2012) annual amplitude of $\Delta$ TWS is substantially dampened (i.e. $45 \%$ less than bottom-up $\Delta$ TWS) in GRCTellus GRACE products relative to GRGS (4\%) and JPL-Mascons (27\% more than bottom-up $\triangle$ TWS) products in the LVB.

The "true" amplitude in the GRCTellus $\triangle$ TWS signal is generally reduced during the post-processing of GRACE spherical harmonic fields, primarily due to spatial smoothing by a large-scale (e.g. $300 \mathrm{~km}$ ) Gaussian filter and truncation of gravity fields at a higher (degree $60=300 \mathrm{~km}$ ) spectral degree (Swenson and Wahr, 2006; Landerer and Swenson, 2012). Despite the application of scaling factors based on CLM v.4.0 to amplify GRCTellus $\triangle$ TWS amplitudes at individual grids, the basin-averaged (LVB) time-series record represents only $75 \%$ variability in bottom-up $\Delta$ TWS. 
Scaling experiments conducted here reveal that GRCTellus $\triangle T W S$ requires an additional multiplicative factor of 1.7 in order to match bottom-up $\triangle \mathrm{TWS}$ with a minimum RMSE $(5.8 \mathrm{~cm})$. On the other hand, NASA's new gridded GRACE product, JPL-Mascons, which applies an a priori constraint in space and time to derive monthly gravity fields and undergoes some degree of spatial smoothing (Watkins et al., 2015), represents nearly $83 \%$ variability in bottom-up $\Delta \mathrm{TWS}$. In contrast, the GRGS GRACE product, which applies truncation at degree $80(\sim 250 \mathrm{~km})$, does not suffer from any largescale spatial smoothing, and is able to represent well $(90 \%)$ the variability in bottom-up $\triangle \mathrm{TWS}$ in the LVB.

A priori corrections of GRCTellus ensemble mean GRACE signals using a set of LSM-derived scaling factors (i.e. amplitude gain) can lead to substantial uncertainty in $\Delta$ TWS (Long et al., 2015). We show that the amplitude of simulated terrestrial water mass over the Upper Nile Basin varies substantially among various LSMs (see Fig. S15). Most of these LSMs (GLDAS models: CLM, NOAH, VIC) do not include surface water or groundwater storage (Scanlon et al., 2012). Although CLM (v.4.0 and 4.5) includes a simple representation (i.e. shallow unconfined aquifer) of groundwater (Niu et al., 2007; Oleson et al., 2008), it does not consider recharge from irrigation return flows. In addition, many of these LSMs do not consider lakes and reservoirs and, most critically, LSMs are not reconciled with in situ observations.

The combined measurement and leakage errors, $\sqrt{ }\left(\right.$ bias $^{2}+$ leak ${ }^{2}$ ) (Swenson and Wahr, 2006) for GRCTellus $\Delta$ TWS based on CLM4.0 model for the LVB and LKB are 7.2 and $6.6 \mathrm{~cm}$ respectively. These values, however, do not represent mass leakage from the lake to the surrounding area within the basin itself. A sensitivity analysis of GRCTellus and GRGS signals reveal that signal leakage occurs from lake to its surrounding basin area as well as between basins. For instance, GRACE signal leakage into the LKB from the LVB, which is 3 times larger in area than the LKB, is 3.4 times bigger for both GRCTellus GRACE and GRGS products. Furthermore, the analysis shows that leakage from Lake Victoria to the LVB for GRCTellus is substantially greater than GRGS product by a factor of $\sim 2.6$. In other words, $1 \mathrm{~mm}$ change in the level of Lake Victoria represents an equivalent change of $0.12 \mathrm{~mm}$ in $\triangle \mathrm{TWS}$ in the LVB for GRCTellus compared to $0.32 \mathrm{~mm}$ for GRGS. Consequently, changes in the amplitude of GRGS $\triangle$ TWS are much greater $(\sim 38 \%)$ than GRCTellus. During the observed reduction in $\triangle \mathrm{TWS}\left(83 \mathrm{~km}^{3}\right)$ from 2003 to 2006, the computed volumetric reduction for GRGS is found to be $69 \mathrm{~km}^{3}$ whereas it is $31 \mathrm{~km}^{3}$ for GRCTellus.

Another source of uncertainty that contributes toward $\triangle T W S$ anomalies in GRACE analysis is the choice of simulated $\triangle$ SMS from various global-scale LSMs (e.g. Shamsudduha et al., 2012; Scanlon et al., 2015). For example, the mean annual (2003-2012) amplitudes in simulated $\Delta$ SMS in GLDAS LSMs (CLM, NOAH, VIC) vary substantially in the $\operatorname{LVB}(3.5,10.2$, and $10.5 \mathrm{~cm})$ and $\operatorname{LKB}(3.7,10.6$, and $7.7 \mathrm{~cm}$ ) respectively. Due to an absence of a dedicated moni- toring network for soil moisture in the Upper Nile Basin, this study, like many other GRACE studies, is resigned to applying simulated $\triangle$ SMS from multiple LSMs, arguing that the use of an ensemble mean minimizes the error associated with $\triangle$ SMS (Rodell et al., 2009).

Computed contributions of $\triangle \mathrm{GWS}$ to $\triangle \mathrm{TWS}$ in the Upper Nile Basin are low $(<10 \%)$. GRACE-derived estimates of $\triangle \mathrm{GWS}$ from all three products (GRCTellus, GRGS, and JPL-Mascons) correlate very weakly with in situ $\Delta \mathrm{GWS}$ in both the LVB and LKB. One curious observation in the LVB during the unintended experiment (2003-2006) is that in situ $\triangle$ GWS rises, whereas in situ $\triangle \mathrm{SWS}$ and simulated $\Delta$ SMS decline. The available evidence in groundwaterlevel records (e.g. Entebbe, Uganda) suggests that rainfallgenerated groundwater recharge led to an increase in $\Delta \mathrm{GWS}$, while dam releases exceeding the agreed curve continued to reduce $\triangle$ SWS (Owor et al., 2011).

Uncertainties in the estimation of GRACE-derived $\triangle \mathrm{GWS}$ remain in (i) accurate representation of the largest individual signal of in situ $\triangle \mathrm{SWS}$ in the disaggregation of GRACE $\triangle \mathrm{TWS}$ signals as it can limit the propagation of uncertainty in simulated $\triangle \mathrm{SMS}$, (ii) simulated $\triangle \mathrm{SMS}$ by GLDAS landsurface models, (iii) the very limited spatial coverage in piezometry to represent in situ $\triangle \mathrm{GWS}$, and (iv) applied $S_{y}$ ( $3 \%$ with a range from 1 to $6 \%$ ) to convert in situ groundwater levels to $\triangle \mathrm{GWS}$. The lack of any strong correlation in GRACE-derived $\triangle \mathrm{GWS}$ and in situ $\triangle \mathrm{GWS}$ time-series records indicates that the magnitude of uncertainty is larger than the overall variability in $\triangle \mathrm{GWS}$ in low-storage, lowtransmissivity weathered crystalline aquifers within the Upper Nile Basin. Furthermore, statistically significant but negative correlations in both the LVB and LKB arise from a positive change in GRACE-derived $\triangle \mathrm{GWS}$ when in situ $\triangle \mathrm{GWS}$ is declining (e.g. 2003-2006 in the LVB; 2008-2010 in the LKB). This inconsistency suggests that the "true" GRACE $\triangle T W S$ signal is weakened during processing and that the combined $\Delta \mathrm{SWS}+\Delta \mathrm{SMS}$ signal is greater than $\Delta \mathrm{TWS}$, mathematically resulting in a positive estimate of $\Delta$ GWS. In contrast to the assertions of Nanteza et al. (2016), applying the GRCTellus CSR solution, we find that this uncertainty prevents robust resolution of $\triangle \mathrm{GWS}$ from GRACE $\triangle \mathrm{TWS}$ in these complex hydrogeological environments of eastern Africa. Despite substantial efforts to improve groundwaterlevel monitoring and to collate existing groundwater-level records across Africa, we recognize that understanding of in situ $\triangle \mathrm{GWS}$ remains greatly constrained by limitations in current observational networks and records. Since present uncertainties and limitations identified in the Upper Nile Basin occur in many of the weathered hard-rock aquifer environments that underlie $40 \%$ of sub-Saharan Africa (MacDonald et al., 2012), tracing of $\triangle \mathrm{GWS}$ using GRACE in these areas is unlikely to be robust until these uncertainties and limitations are better constrained. 


\section{Conclusions}

The analysis of a large, accurately recorded reduction of $1.2 \mathrm{~m}$ in the water level of Lake Victoria, equivalent to a $\Delta$ SWS decline of $81 \mathrm{~km}^{3}$ from 2004 to 2006, exposes substantial variability among five commonly used gridded GRACE products (GRCTellus CSR, JPL, GFZ; GRGS; JPLMascons) to quantify the amplitude of changes in terrestrial water storage ( $\Delta$ TWS). Around this event, we estimate an overall decline in "in situ" or "bottom-up" $\Delta$ TWS (i.e. in situ $\triangle$ SWS and $\Delta$ GWS; simulated $\triangle$ SMS) over the LVB of $83 \mathrm{~km}^{3}$ from 2003 to 2006. This value compares favourably with JPL-Mascons GRACE $\triangle$ TWS $\left(80 \mathrm{~km}^{3}\right)$, is underrepresented by GRGS GRACE $\triangle$ TWS $\left(69 \mathrm{~km}^{3}\right)$, and is substantially underrepresented by the ensemble mean of GRCTellus GRACE $\triangle$ TWS $\left(31 \mathrm{~km}^{3}\right)$. Attempts to better reconcile GRCTellus GRACE $\triangle$ TWS to bottom-up $\triangle$ TWS through scaling techniques are unable to represent adequately the observed amplitude in $\triangle$ TWS but highlight the uncertainty in the amplitude of gridded GRACE $\triangle$ TWS datasets generated by various processing strategies.

From 2003 to 2012, GRGS, JPL-Mascons, and GRCTellus GRACE products trace well the phase in bottom-up $\triangle T W S$ in the Upper Nile Basin that comprises both the LVB and the LKB. In the LVB, for example, each explains $90 \%$ (GRGS), $83 \%$ (JPL-Mascons), and 75\% (GRCTellus ensemble mean of CSR, JPL, and GFZ) of the variance respectively in bottom-up $\triangle$ TWS. The relative proportion of variability in bottom-up $\triangle$ TWS (variance $120 \mathrm{~cm}^{2} \mathrm{LVB}, 24 \mathrm{~cm}^{2}$ LKB) is explained by in situ $\triangle$ SWS (93\% LVB; $49 \%$ LKB), GLDAS ensemble mean $\triangle \mathrm{SMS}$ (6\% LVB; $48 \%$ LKB), and in situ $\Delta \mathrm{GWS}(\sim 1 \% \mathrm{LVB} ; 4 \% \mathrm{LKB})$; these percentages are indicative and can vary as individual TWS components are strongly correlated and the order of explanatory variables in the regression equation can affect the analysis of variance (ANOVA). In situ $\triangle$ GWS contributes minimally to $\triangle$ TWS and is only moderately associated with GRACE $\Delta$ TWS (strongest correlation of $r=0.39, p$ value $<0.001$ ). The resolution of $\triangle$ GWS from GRACE $\triangle$ TWS in the Upper Nile Basin relies upon robust measures of $\Delta$ SWS and $\triangle \mathrm{SMS}$; the former is observed in situ, whereas the latter is limited by uncertainty in simulated $\triangle$ SMS, represented here and in many GRACE studies by an ensemble mean of GLDAS LSMs. Mean annual amplitudes in observed $\triangle$ GWS (2003-2012) from limited piezometry for the low-storage and low-transmissivity aquifers in deeply weathered crystalline rocks that underlie the Upper Nile Basin are small $\left(1.8-4.9 \mathrm{~cm}\right.$ for $\left.S_{y}=0.03\right)$ and, given the current uncertainty in simulated $\triangle \mathrm{SMS}$, are beyond the limit of what can be reliably quantified using current GRACE satellite products.

Our examination of a large, mass-storage change (20032006) observed in the Lake Victoria Basin highlights substantial variability in the measurement of $\Delta$ TWS using different gridded GRACE products. Although the phase in $\triangle \mathrm{TWS}$ is generally well recorded by all tested GRACE products, substantial differences exist in the amplitude of $\Delta$ TWS that influence the disaggregation of individual terrestrial stores (e.g. groundwater storage) and the estimation of temporal trends in TWS. Analyses that solely rely upon a single solution disregard the uncertainty in $\triangle T W S$ associated with GRACE signal processing. We note, for example, that the stronger filtering of the large-scale $(\sim 300 \mathrm{~km})$ gravity signal associated with GRCTellus results in greater signal leakage relative to GRGS and JPL-Mascons. As a result, greater rescaling is required to resurrect signal amplitudes in GRCTellus relative to GRGS and JPL-Mascons and these scaling factors depend upon uncertain and incomplete a priori knowledge of terrestrial water stores derived from largescale land-surface or hydrological models, which generally do not consider the existence of Lake Victoria, the second largest lake by area in the world.

Data availability. Descriptive statistics of various GRACE TWS signals and statistical associations with soil moisture derived from GLDAS land-surface models, observed surface water, and groundwater storage changes estimated over the Lake Victoria and Lake Kyoga basins are provided in the Supplement.

\section{The Supplement related to this article is available online at https://doi.org/10.5194/hess-21-4533-2017- supplement.}

Author contributions. RT conceived this study for which preliminary analyses were carried out by DJ and MS. MS and DJ have processed GRACE and all observational datasets and conducted statistical analyses and GIS mapping. LL conducted the analysis of spatial leakage and bias in GRACE signals. CT, RT and MO helped to establish, collate and analyse groundwater-level data; CT provided dam release data. MS and RT wrote the manuscript and LL, DJ, MO and CT commented on draft manuscripts.

Competing interests. The authors declare that they have no conflict of interest.

Acknowledgements. We kindly acknowledge NASA's MEaSUREs Program (http://grace.jpl.nasa.gov) for the freely available gridded GRCTellus and JPL-MASCON GRACE data and French National Centre for Space Studies (CNES) for GRGS GRACE data. NASA's Precipitation Processing Center and NASA's Hydrological Sciences Laboratory and the Goddard Earth Sciences Data and Information Services Centre (GES DISC) are duly acknowledged for TRMM rainfall and soil moisture data from GLDAS land-surface models. We kindly acknowledge the Directorate of Water Resources Management in the Ministry of Water and Environment (Uganda) for the provision of piezometric and lake-level data. Support from the UK government's UPGro Programme, funded by the Natural Environment Research Council (NERC), Economic and Social Research Council (ESRC) and the Department For International 
Development (DFID) through the GroFutures: Groundwater Futures in Sub-Saharan Africa catalyst (NE/L002043/1) and consortium (NE/M008932/1) grant awards, is gratefully acknowledged.

Edited by: Ying Fan

Reviewed by: two anonymous referees

\section{References}

A, G., Wahr, J., and Zhong, S.: Computations of the viscoelastic response of a 3-D compressible Earth to surface loading: an application to Glacial Isostatic Adjustment in Antarctica and Canada, Geophys. J. Int., 192, 557-572, https://doi.org/10.1093/gji/ggs030, 2013.

Arendt, A. A., Luthcke, S. B., Gardner, A. S., O’Neel, S., Hill, D., Moholdt, G., and Abdalati, W.: Analysis of a GRACE global mascon solution for Gulf of Alaska glaciers, J. Glaciol., 59, 913924, 2013.

Awange, J. L., Sharifi, M. A., Ogonda, G., Wickert, J., Grafarend, E., and Omulo, M.: The falling Lake Victoria water levels: GRACE, TRIMM and CHAMP satellite analysis of the lake basin, Water Resour. Manag., 22, 775-796, 2008.

Awange, J. L., Anyah, R., Agola, N., Forootan, E., and Omondi, P.: Potential impacts of climate and environmental change on the stored water of Lake Victoria Basin and economic implications, Water Resour. Res., 49, 8160-8173, 2013.

Awange, J. L., Forootan, E., Kuhn, M., Kusche, J., and Heck, B.: Water storage changes and climate variability within the Nile Basin between 2002 and 2011, Adv. Water Resour., 73, 1-15, 2014.

Basalirwa, C. P. K.: Delineation of Uganda into climatological rainfall zones using the method of Principle Component Analysis, Int. J. Climatol., 15, 1161-1177, 1995.

Becker, M., Llovel, W., Cazenave, A., Güntner, A., and Crétaux, J.F.: Recent hydrological behaviour of the East African great lakes region inferred from GRACE, satellite altimetry and rainfall observations, C. R. Geosci., 342, 223-233, 2010.

Biancale, R., Lemoine, J.-M., Balmino, G., Loyer, S., Bruisma, S., Perosanz, F., Marty, J.-C., and Gégout, P.: 3 Years of Geoid Variations from GRACE and LAGEOS Data at 10-day Intervals from July 2002 to March 2005, CNES/GRGS, 2006.

Brown, E. and Sutcliffe, J. V.: The water balance of Lake Kyoga, Uganda, Hydrolog. Sci. J., 58, 342-353, https://doi.org/10.1080/02626667.2012.753148, 2013.

Bruinsma, S., Lemoine, J.-M., and Biancale, R.: CNES/GRGS 10-day gravity field models (release 2) and their evaluation Adv. Space Res., 45, 587-601, https://doi.org/10.1016/j.asr.2009.10.012, 2010.

Burgess, W. G., Shamsudduha, M., Taylor, R. G., Zahid, A., Ahmed, K. M., Mukherjee, A., Lapworth, D. J., and Bense, V. F.: Terrestrial water load and groundwater fluctuation in the Bengal Basin, Scientific Reports, 7, 3872, https://doi.org/10.1038/s41598-01704159-w, 2017.

Castellazzi, P., Martel, R., Galloway, D. L., Longuevergne, L., and Rivera, A.: Assessing Groundwater Depletion and Dynamics Using GRACE and InSAR: Potential and Limitations, Ground Water, 54, 768-780, https://doi.org/10.1111/gwat.12453, 2016.
Chen, J. L., Wilson, C. R., and Tapley, B. D.: The 2009 exceptional Amazon flood and interannual terrestrial water storage change observed by GRACE, Water Resour. Res., 46, W12526, https://doi.org/10.1029/2010WR009383, 2010.

Dai, Y., Zeng, X., Dickinson, R. E., Baker, I., Bonan, G. B., Bosilovich, M. G., Denning, A. S., Dirmeyer, P. A., Houser, P. R., Niu, G., Oleson, K. W., Schlosser, C. A., and Yang, Z.-L.: The common land model (CLM), B. Am. Meteorol. Soc., 84, 1013-1023, 2003.

Ek, M. B., Mitchell, K. E., Lin, Y., Rogers, E., Grunmann, P., Koren, V., Gayno, G., and Tarpley, J. D.: Implementation of Noah land surface model advances in the National Centers for Environmental Prediction operational mesoscale Eta model, J. Geophys. Res., 108, 8851, https://doi.org/10.1029/2002JD003296, 2003.

Famiglietti, J. S., Lo, M., Ho, S. L., Bethune, J., Anderson, K. J., Syed, T. H., Swenson, S. C., de Linage, C. R., and Rodell, M.: Satellites measure recent rates of groundwater depletion in California's Central Valley, Geophys. Res. Lett., 38, L03403, https://doi.org/10.1029/2010GL046442, 2011.

Frappart, F., Ramillien, G., and Famiglietti, J. S.: Water balance of the Arctic drainage system using GRACE gravimetry products, Int. J. Remote Sens., 32, 431-453, https://doi.org/10.1080/01431160903474954, 2011.

Güntner, A.: Improvement of Global Hydrological Models Using GRACE Data, Surv. Geophys., 29, 375-397, 2008.

Hoogeveen, J., Faurès, J.-M., Peiser, L., Burke, J., and van de Giesen, N.: GlobWat - a global water balance model to assess water use in irrigated agriculture, Hydrol. Earth Syst. Sci., 19, 3829-3844, https://doi.org/10.5194/hess-19-3829-2015, 2015.

$\mathrm{Hu}$, L. and Jiao, J. J.: Calibration of a large-scale groundwater flow model using GRACE data: a case study in the Qaidam Basin, China, Hydrogeol. J., 23, 1305-1317, 2015.

Huffman, G. J., Adler, R. F., Bolvin, D. T., Gu, G., Nelkin, E. J., Bowman, K. P., Hong, Y., Stocker, E. F., and Wolff, D. B.: The TRMM multi-satellite precipitation analysis: quasi-global, multiyear, combined-sensor precipitation estimates at fine scale, J. Hydrometeorol., 8, 38-55, 2007.

Humphrey, V., Gudmundsson, L., and Seneviratne, S. I.: Assessing Global Water Storage Variability from GRACE: Trends, Seasonal Cycle, Subseasonal Anomalies and Extremes, Surv. Geophys., 37, 357-395, https://doi.org/10.1007/s10712-016-9367-1, 2016.

Indeje, M., Semazzi, F. H. M., and Ogallo, L. J.: ENSO signals in East African rainfall seasons, Int. J. Climatol., 20, 19-46, 2000.

Jacob, T., Wahr, J., Pfeffer, W. T., and Swenson, S.: Recent contributions of glaciers and ice caps to sea level rise, Nature, 482, 514-518, 2012.

Jiang, D., Wang, J., Huang, Y., Zhou, K., Ding, X., and Fu, J.: The Review of GRACE Data Applications in Terrestrial Hydrology Monitoring, Advances in Meteorology, 2014, 725131, https://doi.org/10.1155/2014/725131, 2014.

Khandu, Forootan, E., Schumacher, M., Awange, J. L., and Schmied, H. M.: Exploring the influence of precipitation extremes and humanwater use on total water storage (TWS)changes in the Ganges-BrahmaputraMeghna River Basin, Water Resour. Res., 52, 2240-2258, https://doi.org/10.1002/2015WR018113, 2016.

Kim, H., Yeh, P. J.-F., Oki, T., and Kanae, S.: Role of rivers in the seasonal variations of terrestrial water stor- 
age over global basins, Geophys. Res. Lett., 36, L17402, https://doi.org/10.1029/2009GL039006, 2009.

Kizza, M., Westerberg, I., Rodhe, A., and Ntale, H.: Estimating areal rainfall over Lake Victoria and its basin using ground-based and satellite data, J. Hydrol., 464-465, 401-411, 2012.

Krishnamurthy, K. V. and Ibrahim, A. M.: Hydrometeorological Studies of Lakes Victoria, Kyoga, and Albert, in: Man-made Lakes: Their Problems and Environmental Effects, edited by: Ackermann, W. C., White, G. F., Worthington, E. B., and Ivens, J. L., American Geophysical Union, Washington D.C., 272-277, 1973.

Kusche, J., Eicker, A., Forootan, E., Springer, A., and Longuevergne, L.: Mapping probabilities of extreme continental water storage changes from space gravimetry, Geophys. Res. Lett., 43, 8026-8034, https://doi.org/10.1002/2016GL069538, 2016.

Landerer, F. W. and Swenson, S. C.: Accuracy of scaled GRACE terrestrial water storage estimates, Water Resour. Res., 48, W04531, https://doi.org/10.1029/2011WR011453, 2012.

Leblanc, M. J., Tregoning, P., Ramillien, G., Tweed, S. O., and Fakes, A.: Basin-scale, integrated observations of the early 21st century multiyear drought in southeast Australia, Water Resour. Res., 45, W04408, https://doi.org/10.1029/2008WR007333, 2009.

Lehner, B., Verdin, K., and Jarvis, A.: HydroSHEDS technical documentation, World Wildlife Fund, Washington D.C., 2006.

Lehner, B., Verdin, K., and Jarvis, A.: New global hydrography derived from spaceborne elevation data, Eos T. Am. Geophys. Un., 89, 93-94, 2008.

Lemoine, J.-M., Bruisma, S., Loyer, S., Biancale, R., Marty, J.-C., Perosanz, F., and Balmino, G.: Temporal gravity field models inferred from GRACE data, Adv. Space Res., 39, 1620-1629, https://doi.org/10.1016/j.asr.2007.03.062, 2007.

Liang, X., Xie, Z., and Huang, M.: A new parameterization for surface and groundwater interactions and its impact on water budgets with the variable infiltration capacity (VIC) land surface model, J. Geophys. Res., 108, 8613, https://doi.org/10.1029/2002JD003090, 2003.

Long, D., Longuevergne, L., and Scanlon, B. R.: Global analysis of approaches for deriving total waterstorage changes from GRACE satellites, Water Resour. Res., 51, 2574-2594, https://doi.org/10.1002/2014WR016853, 2015.

Long, D., Chen, X., Scanlon, B. R., Wada, Y., Hong, Y., Singh, V. P., Chen, Y., Wang, C., Han, Z., and Yang, W.: Have GRACE satellites overestimated groundwater depletion in the Northwest India Aquifer?, Nature Scientific Reports, 6, 24398, https://doi.org/10.1038/srep24398, 2016.

Long, D., Pan, Y., Zhou, J., Chen, Y., Hou, X., Hong, Y., Scanlon, B. R., and Longuevergne, L.: Global analysis of spatiotemporal variability in merged total water storage changes using multiple GRACE products and global hydrological models, Remote Sens. Environ., 192, 198-216, 2017.

Longuevergne, L., Scanlon, B. R., and Wilson, C. R.: GRACE hydrological estimates for small basins: evaluating processing approaches on the High Plains Aquifer, USA, Water Resour. Res., 46, W11517, https://doi.org/10.1029/2009WR008564, 2010.

Longuevergne, L., Wilson, C. R., Scanlon, B. R., and Crétaux, J. F.: GRACE water storage estimates for the Middle East and other regions with significant reservoir and lake storage, Hydrol. Earth
Syst. Sci., 17, 4817-4830, https://doi.org/10.5194/hess-17-48172013, 2013.

MacDonald, A. M., Bonsor, H. C., Dochartaigh, B. E. O., and Taylor, R. G.: Quantitative maps of groundwater resources in Africa, Environ. Res. Lett., 7, 024009, https://doi.org/10.1088/17489326/7/2/024009, 2012.

Nanteza, J., de Linage, C. R., Thomas, B. F., and Famiglietti, J. S.: Monitoring groundwater storage changes in complex basement aquifers: An evaluation of the GRACE satellites over East Africa, Water Resour. Res., 52, 9542-9564, https://doi.org/10.1002/2016WR018846, 2016.

Nicholson, S. E., Yin, X., and Ba, M. B.: On the feasibility of using a lake water balance model to infer rainfall: an example from Lake Victoria, Hydrolog. Sci. J., 45, 75-95, 2000.

Niu, G.-Y., Yang, Z.-L., Dickinson, R. E., Gulden, L. E., and $\mathrm{Su}, \mathrm{H}$.: Development of a simple groundwater model for use in climate models and evaluation with Gravity Recovery and Climate Experiment data, J. Geophys. Res., 112, D07103, https://doi.org/10.1029/2006JD007522, 2007.

Oleson, K. W., Niu, G.-Y., Yang, Z.-L., Lawrence, D. M., Thornton, P. E., Lawrence, P. J., Stockli, R., Dickinson, R. E., Bonan, G. B., Levis, S., Dai, A., and Qian, T.: Improvements to the Community Land Model and their impact on the hydrological cycle, J. Geophys. Res., 113, G01021, https://doi.org/10.1029/2007JG000563, 2008.

Owor, M.: Groundwater - surface water interactions on deeply weathered surfaces of low relief in the Upper Nile Basin of Uganda, PhD thesis, Geography, University College London, London, 271 pp., 2010.

Owor, M., Taylor, R. G., Tindimugaya, C., and Mwesigwa, D.: Rainfall intensity and groundwater recharge: empirical evidence from the Upper Nile Basin, Environ. Res. Lett., 4, 035009, https://doi.org/10.1088/1748-9326/4/3/035009, 2009.

Owor, M., Taylor, R. G., Mukwaya, C., and Tindimugaya, C.: Groundwater/surface-water interactions on deeply weathered surfaces of low relief: evidence from Lakes Victoria and Kyoga, Uganda, Hydrogeol. J., 19, 1403-1420, 2011.

Ramillien, G., Famiglietti, J. S., and Wahr, J.: Detection of Continental Hydrology and Glaciology Signals from GRACE: A Review, Surv. Geophys., 29, 361-374, 2008.

Rodell, M. and Famiglietti, J. S.: Terrestrial Water Storage Variations over Illinois: Analysis of Observations and Implications for GRACE, Water Resour. Res., 37, 1327-1340, 2001.

Rodell, M., Houser, P. R., Jambor, U., Gottschalck, J., Mitchell, K., Meng, C.-J., Arsenault, K., Cosgrove, B., Radakovich, J., Bosilovich, M., Entin, J. K., Walker, J. P., Lohmann, D., and Toll, D.: The Global Land Data Assimilation System, B. Am. Meteorol. Soc., 85, 381-394, 2004.

Rodell, M., Velicogna, I., and Famiglietti, J. S.: Satellite-based estimates of groundwater depletion in India, Nature, 460, 999-1003, https://doi.org/10.1038/nature08238, 2009.

Rowlands, D. D., Luthcke, S. B., McCarthy, J. J., Klosko, S. M., Chinn, D. S., Lemoine, F. G., Boy, J.-P., and Sabaka, T. J.: Global mass fluxsolutions from GRACE: A comparison of parameter estimation strategies-Mass concentrations versus stokes coe?cients, J. Geophys. Res., 115, B01403, https://doi.org/10.1029/2009JB006546, 2010.

Scanlon, B. R., Longuevergne, L., and Long, D.: Ground referencing GRACE satellite estimates of groundwater storage changes 
in the California Central Valley, USA, Water Resour. Res., 48, W04520, https://doi.org/10.1029/2011WR011312, 2012.

Scanlon, B. R., Zhang, Z., Reedy, R. C., Pool, D. R., Save, H., Long, D., Chen, J., Wolock, D. M., Conway, B. D., and Winester, D.: Hydrologic implications of GRACE satellite data in the Colorado River Basin, Water Resour. Res., 51, 9891-9903, https://doi.org/10.1002/2015WR018090, 2015.

Scanlon, B. R., Zhang, Z., Save, H., Wiese, D. N., Landerer, F. W., Long, D., Longuevergne, L., and Chen, J.: Global evaluation of new GRACE mascon products for hydrologic applications, Water Resour. Res., 52, 9412-9429, https://doi.org/10.1002/2016WR019494, 2016.

Sene, K. J. and Plinston, D. T.: A review and update of the hydrology of Lake Victoria in East Africa, Hydrolog. Sci. J., 39, 47-63, 1994.

Shamsudduha, M., Taylor, R. G., and Longuevergne, L.: Monitoring groundwater storage changes in the highly seasonal humid tropics: validation of GRACE measurements in the Bengal Basin, Water Resour. Res., 48, W02508, https://doi.org/10.1029/2011WR010993, 2012.

Strassberg, G., Scanlon, B. R., and Rodell, M.: Comparison of seasonal terrestrial water storage variations from GRACE with groundwater-level measurements from the High Plains Aquifer (USA), Geophys. Res. Lett., 34, L14402, https://doi.org/10.1029/2007GL030139, 2007.

Sun, A. Y., Green, R., Rodell, M., and Swenson, S.: Inferring aquifer storage parameters using satellite and in situ measurements: Estimation under uncertainty, Geophys. Res. Lett., 37, L10401, https://doi.org/10.1029/2010GL043231, 2010.

Sutcliffe, J. V. and Petersen, G.: Lake Victoria: derivation of a corrected natural water level series, Hydrolog. Sci. J., 52, 13161321, 2007.

Swenson, S. and Wahr, J.: Post-processing removal of correlated errors in GRACE data, Geophys. Res. Lett., 33, L08402, https://doi.org/10.1029/2005GL025285, 2006.

Tapley, B., Flechtner, F., Watkins, M., and Bettadpur, S.: GRACE mission: status and prospects, 2015 GRACE Science Team Meeting, Austin, Texas, 20-22 September, 2015.

Tapley, B. D., Bettadpur, S., Ries, J. C., Thompson, P. F., and Watkins, M. M.: GRACE measurements of mass variability in the Earth system, Science, 305, 503-505, 2004.

Taylor, R. G. and Howard, K. W. F.: A tectonic geomorphic model of the hydrogeology of deeply weathered crystalline rock: evidence from Uganda, Hydrogeol. J., 8, 279-294, 2000.

Taylor, R. G., Tindimugaya, C., Barker, J., MacDonald, D., and Kulabako, R.: Convergent radial tracing of viral and solute transport in gneiss saprolite, Ground Water, 48, 284-294, 2010.
Taylor, R. G., Todd, M. C., Kongola, L., Maurice, L., Nahozya, E., Sanga, H., and MacDonald, A. M.: Evidence of the dependence of groundwater resources on extreme rainfall in East Africa, Nature Climate Change, 3, 374-378, https://doi.org/10.1038/nclimate1731, 2013.

UNEP: Adaptation to Climate-change Induced Water Stress in the Nile Basin: A Vulnerability Assessment Report, Division of Early Warning and Assessment (DEWA), United Nations Environment Programme (UNEP), Nairobi, Kenya, 2013.

Vishwakarma, B. D., Devaraju, B., and Sneeuw, N.: Minimizing the effects of filtering on catchment scale GRACE solutions, Water Resour. Res., 52, 5868-5890, https://doi.org/10.1002/2016WR018960, 2016.

Vouillamoz, J. M., Lawson, F. M. A., Yalo, N., and Descloitres, M.: The use of magnetic resonance sounding for quantifying specific yield and transmissivity in hard rock aquifers: The example of Benin, J. Appl. Geophys., 107, 16-24, 2014.

Wahr, J., Swenson, S., Zlotnicki, V., and Velicogna, I.: Timevariable gravity from GRACE: First results, Geophys. Res. Lett., 31, L11501, https://doi.org/10.1029/2004GL019779, 2004.

Wahr, J., Swenson, S., and Velicogna, I.: Accuracy of GRACE mass estimates, Geophys. Res. Lett., 33, L06401, https://doi.org/10.1029/2005GL025305, 2006.

Wang, L., Davis, J. L., Hill, E. M., and Tamisiea, M. E.: Stochastic filtering for determining gravityvariations for decade-long timeseries of GRACE gravity, J. Geophys. Res.-Sol. Ea., 121, 29152931, https://doi.org/10.1002/2015JB012650, 2016.

Watkins, M. M., Wiese, D. N., Yuan, D.-N., Boening, C., and Landerer, F. W.: Improved methods for observing Earth's time variable mass distribution with GRACE using spherical cap mascons, J. Geophys. Res.-Sol. Ea., 120, 2648-2671, https://doi.org/10.1002/2014JB011547, 2015.

Wiese, D. N., Yuan, D.-N., Boening, C., Landerer, F. W., and Watkins, M. M.: JPL GRACE Mascon Ocean, Ice, and Hydrology Equivalent Water Height JPL RL05M.1. Ver. 1, PO.DAAC, CA, USA, 2015.

Wiese, D. N., Landerer, F. W., and Watkins, M. M.: Quantifying and reducing leakage errors in the JPL RL05M GRACE mascon solution, Water Resour. Res., 52, 7490-7502, https://doi.org/10.1002/2016WR019344, 2016.

Xie, H., Longuevergne, L., Ringler, C., and Scanlon, B. R.: Calibration and evaluation of a semi-distributed watershed model of Sub-Saharan Africa using GRACE data, Hydrol. Earth Syst. Sci., 16, 3083-3099, https://doi.org/10.5194/hess-16-3083-2012, 2012.

Yin, X. and Nicholson, S. E.: The water balance of Lake Victoria, Hydrolog. Sci. J., 43, 789-811, 1998. 